\title{
Ground-based validation of the MetopA and B GOME-2 OCIO measurements
}

Gaia Pinardi ${ }^{1}$, Michel Van Roozendael ${ }^{1}$, François Hendrick ${ }^{1}$, Andreas Richter $^{2}$, Pieter Valks ${ }^{3}$, Ramina Alwarda ${ }^{4}$, Kristof Bognar ${ }^{*}$, Udo Frieß ${ }^{5}$, José Granville ${ }^{1}$, Myojeong Gu ${ }^{6}$, Paul Johnston ${ }^{7}$, Cristina Prados-Roman ${ }^{8}$, Richard Querel ${ }^{7}$, Kimberly Strong ${ }^{4}$, Thomas Wagner ${ }^{6}$, Folkard Wittrock ${ }^{2}$, and Margarita Yela Gonzalez ${ }^{8}$

${ }^{1}$ Royal Belgian Institute for Space Aeronomy (BIRA-IASB), Av Circulaire 3, 1180 Uccle, Belgium

${ }^{2}$ Institute of Environmental Physics (IUPB), University of Bremen, Otto-Hahn-Allee 1, D-28359 Bremen, Germany

${ }^{3}$ Deutsches Zentrum für Luft-und Raumfahrt (DLR), Institut für Methodik der Fernerkundung (IMF), Münchener Str. 20, D-82234, Oberpfaffenhofen, Germany

${ }^{4}$ Department of Physics, University of Toronto, 60 St. George Street, Toronto, Ontario, M5S 1A7, Canada

${ }^{5}$ Institute of Environmental Physics (IUPH), University of Heidelberg, Im Neuenheimer Feld 229, Heidelberg, Germany

${ }^{6}$ Max-Planck-Institut für Chemie (MPIC), Hahn-Meitner-Weg 1, 55128 Mainz, Germany

${ }^{7}$ National Institute of Water and Atmospheric Research (NIWA), Private Bag 50061, Omakau, Central Otago, New Zealand

${ }^{8}$ Atmospheric Research and Instrumentation Branch, National Institute for Aerospace Technology (INTA), Madrid, 28850, Spain

*Now at: Institute of Space and Atmospheric Studies, University of Saskatchewan, Saskatoon, Saskatchewan, Canada

Correspondence: Gaia Pinardi (gaia.pinardi@aeronomie.be)

Abstract. This paper reports on ground-based validation of the atmospheric $\mathrm{OClO}$ data record produced in the framework of EUMETSAT's Satellite Application Facility on Atmospheric Chemistry Monitoring (AC SAF) using the GOME2-A and -B instruments over the 2007-2016 and 2013-2016 periods, respectively. OClO slant column densities are compared to correlative measurements collected from 9 NDACC Zenith-Scattered-Light DOAS (ZSL-DOAS) instruments distributed in both the

Arctic and Antarctic. Sensitivity tests are performed on the ground-based data to estimate the impact of the different OClO DOAS analysis settings. On this basis, we infer systematic uncertainties of about $25 \%$ between the different ground-based data analysis, reaching total uncertainties ranging from about $26 \%$ to $33 \%$ for the different stations. Time-series at the different sites show good agreement between satellite and ground-based data, both for the inter-annual variability and the overall OClO seasonal behaviour. GOME-2A results are found to be nosier than those of GOME-2B, especially after 2011, probably due to instrumental degradation effects. Daily linear regression analysis for OClO activated periods yield correlation coefficients of 0.8 for GOME-2A and 0.87 for GOME-2B, with slopes of 0.64 and 0.72 , respectively. Biases are within $8 \times 10^{13} \mathrm{molec} / \mathrm{cm}^{2}$ with some differences between GOME-2A and GOME-2B, depending on the station. Overall, considering all the stations, a median bias of about $-2.2 \times 10^{13} \mathrm{molec} / \mathrm{cm}^{2}$ is found for both GOME-2 instruments. 


\section{Introduction}

The increase of the chlorine and bromine species in the stratosphere, due to the anthropogenic release of long-lived halogenated compounds, has led to dramatic ozone losses in the polar winter stratosphere starting in the eighties (e.g. Solomon et al., 1988, 1990; Solomon, 1999).

In polar regions, the chemical destruction of ozone is strongly influenced by the polar vortex, which results from the largescale descent of cold air masses during winter. The polar vortex is also associated to strong Coriolis-related circumpolar winds that prevent air mixing with lower latitudes. In the Northern Hemisphere, due to the inhomogeneous distribution of land masses, disturbances of the Arctic vortex by vertical propagation of planetary waves is frequent, while the Antarctic vortex usually remains stable and more or less symmetric until at least late spring (November).

During winter, temperatures inside the vortex can drop below the threshold for the formation of polar stratospheric clouds (PSCs), and heterogeneous reactions on PSC-particles convert ozone-inert chlorine reservoirs (mainly $\mathrm{ClONO}_{2}$ and $\mathrm{HCl}$ ) into ozone destroying species (active chlorine, mainly $\mathrm{Cl}, \mathrm{ClO}$ and $\mathrm{ClOOCl}$ ), see, e.g., Solomon (1999). This chlorine activation is the prerequisite for ozone destruction by catalytic cycles like the $\mathrm{ClO}-\mathrm{ClO}$ and the $\mathrm{ClO}-\mathrm{BrO}$ cycle (McElroy et al., 1986; Molina and Molina, 1987) after the return of sunlight in the polar spring. OClO is mostly created by the reaction between $\mathrm{ClO}$ and $\mathrm{BrO}(\mathrm{ClO}+\mathrm{BrO} \rightarrow \mathrm{OClO}+\mathrm{Br})$ (Solomon et al., 1987; Toumi, 1994; Renard et al., 1997). OClO has a very short lifetime of a few seconds in the sunlit atmosphere due to its photolysis $(\mathrm{OClO}+\mathrm{h} \nu \rightarrow \mathrm{ClO}+\mathrm{O})$, which prevents the build-up of significant amounts until large solar zenith angles (SZAs) are reached. Nighttime and twilight OClO are thus a good indicator of chlorine activation (Sessler et al., 1995; Renard et al., 1997; Tørnkvist et al., 2002). Although OClO is only formed in sizeable quantities during the night, solar backscatter measurements of OClO columns can be performed from space near the terminator where the photolysis efficiency is reduced.

The emission of long-lived chlorine and bromine containing substances has been regulated since 1987 after the implementation of the Montreal Protocol and its amendments. As a result, atmospheric levels of the ozone-destroying precursor substances have decreased over the last decades. Monitoring of stratospheric chlorine and bromine contents remains important to assess the effectiveness of the regulatory measures taken, in particular in the context of climate change and its impact on ozone recovery.

Halogen oxides such as $\mathrm{BrO}$ and $\mathrm{OClO}$ can be measured using the Differential Optical Absorption Spectroscopy (DOAS) method (Platt and Stutz, 2008) owing to their structured absorption cross-sections in the UV and visible parts of the spectrum. For OClO, the first detection from the ground was reported by Solomon et al. (1987) in Antarctica, and subsequently by many other measurements in both hemispheres (Solomon et al., 1988, 1990; Gil et al., 1996; Kreher et al., 1996; Otten et al., 1998; Richter et al., 1999; Tørnkvist et al., 2002; Vandaele et al., 2005; Frieß et al., 2005). Observations from aircraft (Schiller et al., 1990) and from balloons (Pommereau and Piquard, 1994; Renard et al., 1997) followed.

45 The first $\mathrm{OClO}$ retrievals from nadir satellite data were performed using the Global Ozone Monitoring Experiment (GOME) by Wagner et al. (2001, 2002); Burrows et al. (1999); Kühl et al. (2004) and Richter et al. (2005). This was followed by measurements from the Scanning Imaging Spectrometer for Atmospheric Chartography (SCIAMACHY, Kühl et al. (2006)), the 
Ozone Monitoring Instrument (OMI, OMOCLOv3), GOME-2 (Richter et al., 2015; Valks et al., 2019a, b), and the TROPOspheric Monitoring Instrument (TROPOMI, Meier et al. (2020); Pukīte et al. (2021a, b)).

Richter et al. (2015) illustrated the possibility to retrieve consistent dataset of OClO slant column densities (SCDs) from both GOME-2A and GOME-2B sensors. Settings proposed by Richter et al. (2015) study were implemented at DLR for the AC SAF data products (Hassinen et al., 2016) within the GOME Data processor (GDP) 4.8 (Valks et al., 2019a, b) for the period 2007 to 2016, and are under focus in this study.

These global long-term nadir satellite datasets offer interesting perspectives to study inter-hemispheric and inter-annual differences in the activation of halogens, their dependence on meteorological parameters and their long-term trends. To allow for reliable exploitation of the long time-series (starting in 1995 with GOME), it is essential to validate the different data sets. At present, to our knowledge, only a small number of studies quantitatively intercompared OClO datasets, and mostly on a few seasons/episodes/years (Oetjen et al., 2011; Richter et al., 2015; Kühl et al., 2006; Pukīte et al., 2021a, b).

In this paper we present a validation approach focusing on polar regions, by addressing the quality of the GOME-2A and GOME-2B OCIO ACSAF data records over 8 stations, during the time-period from 2007 until 2016. The satellite slant columns are compared to correlative observations acquired by independent ground-based DOAS spectrometers in zenith-sky geometry and the results for both satellites are compared and discussed. The paper is organized as follows: Section 2 presents the OClO algorithm applied to GOME-2, while Sect. 3 presents the ground-based ZSL-DOAS datasets and the comparisons method. The validation results are discussed in Sect. 4 and conclusions are given in Sect. 5.

\section{GOME-2 OClO data}

The second Global Ozone Monitoring Instrument (GOME-2) is a nadir-looking UV-visible spectrometer measuring the solar radiation backscattered by the atmosphere and reflected by the Earth surface and clouds in the 240-790 nm wavelength interval at a spectral resolution of 0.2-0.5 nm full width at half maximum (FWHM) (Munro et al., 2016). There are three GOME-2 instruments flying on Sun-synchronous polar orbits on board the Meteorological Operational satellites (MetOp-A, MetOp-B and MetOp-C, launched in October 2006, September 2012, and November 2018, respectively). They have an Equator crossing time of 09:00-09:30 local time in the descending node. The default swath width of the GOME-2 across-track scan is $1920 \mathrm{~km}$, allowing global Earth coverage within 1.5-3 days at the Equator, with a nominal ground pixel size of $80 \times 40 \mathrm{~km}^{2}$. Since 15 July 2013, GOME-2A is measuring on a reduced swath mode of $960 \mathrm{~km}$, with a ground pixel size of $40 \times 40 \mathrm{~km}^{2}$.

Following the initial study of Richter et al. (2009), an improved OClO slant column retrieval algorithm was developed for both GOME-2A and -B in the framework of an AC SAF Visiting Scientist project (Richter et al., 2015). This led to a clear improvement compared to earlier results. The settings, summarized in Table 1, were implemented by DLR in the AC SAF product portfolio as GDP 4.8 data records for GOME-2A (2007-2016) and GOME-2B (2012-2016). These data products can be found on the acsaf.eoc.dlr.de FTP server. 
The GOME-2 GDP 4.8 OClO retrieval algorithm is fully described in the corresponding Algorithm Theoretical Basis Document (Valks et al., 2019a) and detailed information about the development of the analysis can be found in Richter et al. (2015).

The DOAS retrieval is performed in the UV wavelength range 345-389nm which was found to minimise both bias and noise in retrieved $\mathrm{OClO}$ slant columns. The fit includes $\mathrm{NO}_{2}, \mathrm{O}_{3}, \mathrm{O}_{2}-\mathrm{O}_{2}$ and the Ring effect (see Table 1). The GOME-2 key data parameter Eta is included as another effective cross-section to correct for residual polarization errors in the level-1 product. This inclusion significantly improves the $\mathrm{OClO}$ fitting residuals. Two empirical correction functions (derived from mean DOAS-fit residuals) are also included as additional (pseudo-) absorption cross-sections in the DOAS-fit: a mean residual and a scan angle correction function. These two empirical functions correct for positive offsets and scan angle dependencies in the OClO columns. Remaining biases in the OClO columns (e.g. non-zero OClO columns over areas without chlorine activation), with temporal drifts observed mainly in the OClO data from GOME-2A (see Richter et al. (2015)), need to be treated using an additional offset correction. A simple normalization is thus applied on an orbital basis. The mean OClO slant column for the area between $50^{\circ} \mathrm{N}$ and $50^{\circ} \mathrm{S}$ (a latitude region without chlorine activation) is determined for each GOME-2 orbit,and subtracted from the retrieved $\mathrm{OClO}$ slant columns for the complete orbit, leading to normalized OClO slant columns (SCD).

Table 1. DOAS settings used for the GOME-2 OClO retrieval in GDP 4.8.

\begin{tabular}{l|c}
\hline Variable & Detail \\
\hline $\begin{array}{l}\text { Fitting interval } \\
\text { Wavelength }\end{array}$ & $345-389 \mathrm{~nm}$ \\
calibration & $\begin{array}{c}\text { Sun irradiance for GOME-2 L1 product } \\
\text { Calibration of sun reference } \\
\text { optimized by NLLS adjustment on } \\
\text { convolved Chance and Spurr solar lines atlas } \\
\text { Polynomial }\end{array}$ \\
Offset & lth order, 5 coefficients \\
Absorption & linear \\
cross-sections: & \\
- OClO & Kromminga et al. (2003)(213K) \\
- $\mathrm{NO}_{2}$ & Gür et al. (2005) (223K) \\
- $\mathrm{O}_{3}$ & Gür et al. (2005) (223K and 243K) \\
- $\mathrm{O}_{2}$ - $\mathrm{O}_{2}$ & Hermans et al. (1999) \\
- Ring effect & Vountas et al. (1998) \\
- Key data & Eta \\
- Empirical functions & mean residual and scan angle correction \\
\hline
\end{tabular}

An illustration of OClO SCD maps for the Arctic in February 2011 and the Antarctic in August 2015 is given in Fig. 1. 


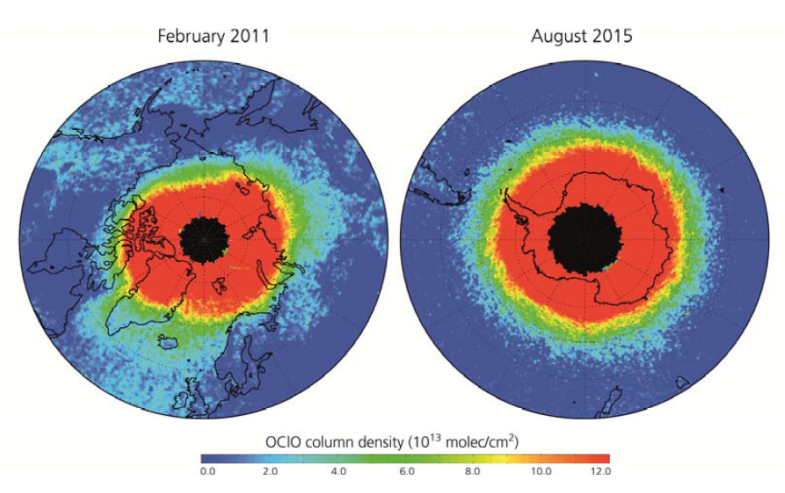

Figure 1. GOME-2 OClO maps for February 2011 and August 2015. stances the calculation of an AMF and a vertical column is not trivial. It is complicated by rapid photolysis, the change in SZA along the line of sight, and also the uncertainty in the OClO vertical profile (Richter et al., 2005; Oetjen et al., 2011). Therefore, as done in previous studies, the GOME-2 GDP data product only contains (normalized) OClO slant columns densities (SCD).

A flag indicates when valid (enhanced) OClO column values can be expected from the GOME-2 data. The OClO flag is set to 1 for daylight measurements with large solar zenith angle $\left(85^{\circ}<\mathrm{SZA}<89^{\circ}\right)$ and it is set to 2 for measurement during twilight $\left(89^{\circ}<\mathrm{SZA}<92^{\circ}\right)$, see (Valks et al., 2019b).

Figure 2 illustrates the GOME-2A and B datasets, by presenting the daily $90^{\circ}$ SZA OClO SCD averages of both instruments, separated by hemisphere. As expected, OClO levels in the Southern hemisphere are usually larger than in the Northern hemisphere, and the year-to-year variability is larger in the latter. E.g., lower chlorine activation levels are found in 2009 and 2013 in the Northern hemisphere compared to other years. Outside the chlorine activation period, values should be very close to 0 in both hemispheres. This is usually the case in the first years of measurements of each instrument, although some negative or positive offsets (of up to 4 to $5 \times 10^{13} \mathrm{molec} / \mathrm{cm}^{2}$ ) appear for some of the years (e.g. 2010 in the Northern hemisphere or 2011, 2012 and 2013 for southern hemisphere for GOME-2A). These results suggest that there is still room for improvement in the current GOME-2 analysis.

\section{Comparison data and method}

\subsection{Ground-based NDACC ZSL-DOAS data}

As stated in the introduction, OClO columns have been retrieved from the ground since 1986 using the DOAS technique. For this study we selected 8 stations operating Zenith-Scattered sun Light (ZSL)-DOAS UV-Visible spectrometers from the Network for the Detection of Atmospheric Composition Change (NDACC, https://www.ndaccdemo.org/, last access on 28 June 2021), located above $60^{\circ}$ latitude in both hemispheres and performing OClO SCD data retrievals. The geographical 


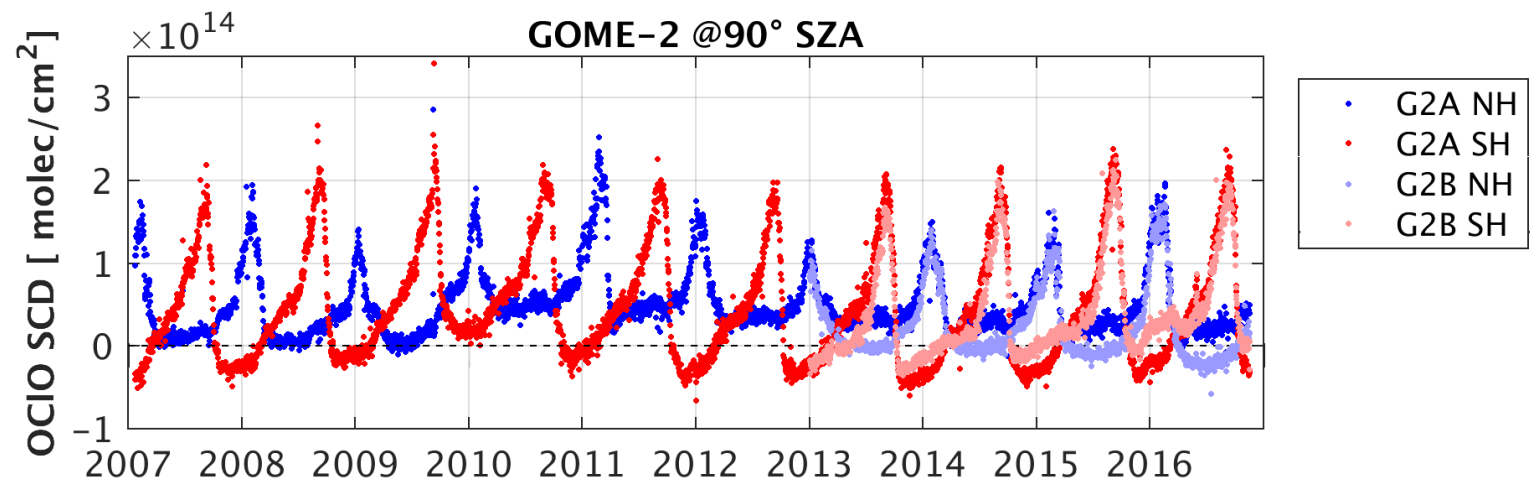

Figure 2. Daily GOME-2 OClO SCD time series for SZA $=90 \pm 1^{\circ}$.

distribution of these instruments is represented in Fig. 3 and a more extensive descriptions of the sites is given in Annex A1. This dataset provides a good temporal coverage, some of the stations reporting observations over the whole Metop-A operation period (2007-2016). A good coverage of the Arctic and Antarctic region is also achieved, with half of the stations in the Northern Hemisphere and half in the Southern Hemisphere. This ensemble of stations was also recently used for the validation of TROPOMI OClO SCDs (Pinardi et al., 2020).

Specific details on the OCIO SCD analysis are given in Table 2. As further described in Sect. 3.2, ground-based measurements are extracted at the solar zenith angle of the recorded GOME-2 pixels, for optimal photochemical coincidence with satellite observations. A fixed reference spectrum selected outside of the activated vortex period ensures that no OClO contribution comes from the reference, providing in this way absolute slant columns. For the UToronto instrument in Eureka, some instrumental instabilities prevented the use of one yearly fixed spectrum for the analysis of some of the years, leading to a reduced temporal coverage of the comparisons (see Fig. 13 and 14).

From Table 2 it is clear that the ensemble of ground-based datasets is an aggregate of existing measurements and there is no harmonization in the retrieval choices of the different groups processing the OClO data. Different wavelength regions were used by each group for the $\mathrm{OClO}$ analysis, depending mainly on the spectral range covered by the respective instruments (see Table A1 for the instrumental details). In most cases, retrievals were performed in the UV region between 345 and $392 \mathrm{~nm}$. One exception is NIWA who analysed its data in the visible spectral range (404-425nm, Kreher et al. (1996)). An illustration of the different $\mathrm{OClO}$ bands used in the different intervals is presented in Figure 4.

Another important difference is related to the OClO cross-section used, and its temperature. It can be seen that most of the groups use the Kromminga et al. (2003) cross-sections, while IUPB adopted the Kromminga et al. (1999) and UToronto the Wahner et al. (1987) dataset at 204K. Moreover, within groups having adopted the Kromminga et al. (2003) data, most of them used the $213 \mathrm{~K}$ dataset, while INTA and IUPH used the $233 \mathrm{~K}$ dataset. 
https://doi.org/10.5194/amt-2021-356

Preprint. Discussion started: 29 November 2021

(c) Author(s) 2021. CC BY 4.0 License.

(c) (i)

\section{Atmospheric Measurement \\ Techniques \\ Discussions}

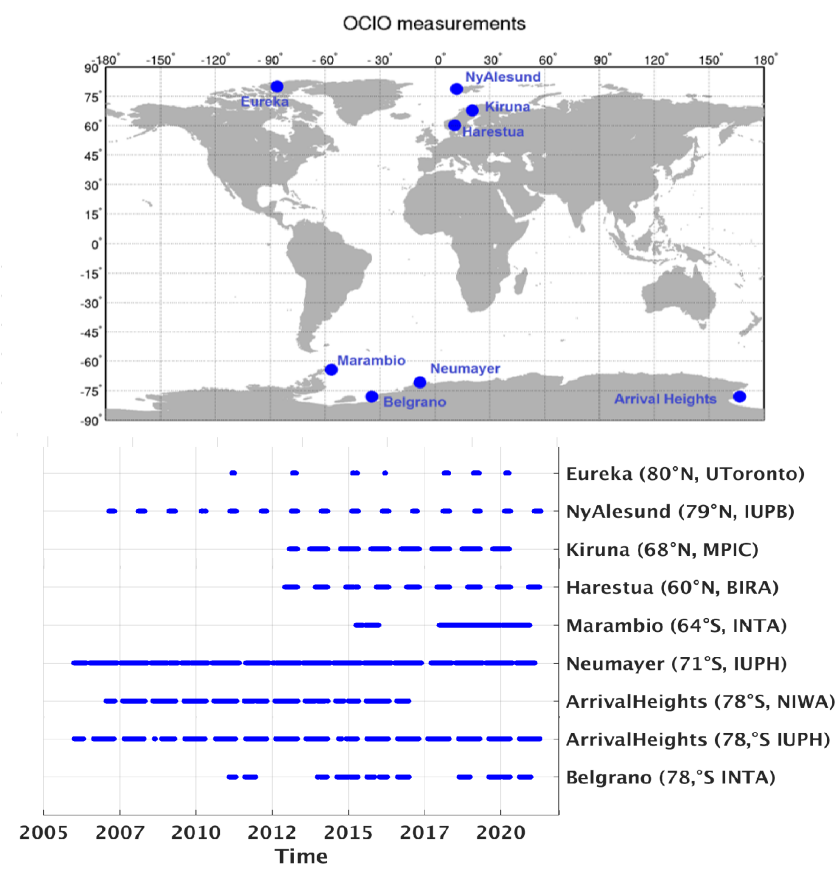

Figure 3. Geographical distribution and measurement time-periods of the UV-visible NDACC ZSL-DOAS instruments providing the correlative $\mathrm{OClO}$ measurements.

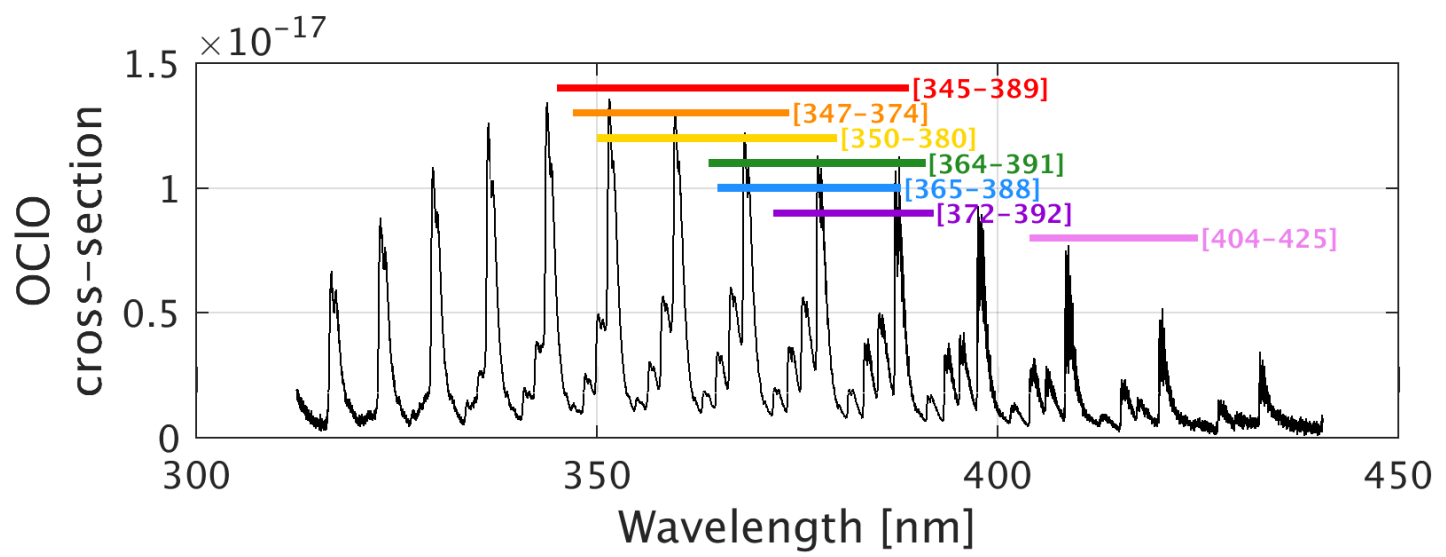

Figure 4. OClO absorption cross-section at 213K from Kromminga et al. (2003) and the different DOAS intervals used in this study.

Depending on the selected DOAS interval, the different groups include in their DOAS fit several other trace gas crosssections $\left(\mathrm{NO}_{2}, \mathrm{O}_{3}, \mathrm{BrO}, \mathrm{O}_{4}\right)$ in addition to OClO. Also they treat the Ring effect as a pseudo-absorber. Not all the absorbers 
https://doi.org/10.5194/amt-2021-356

Preprint. Discussion started: 29 November 2021

(C) Author(s) 2021. CC BY 4.0 License.
Atmospheric

Measurement

Techniques

Discussions

Table 2. Description of the different ground-based OClO datasets used in this study.

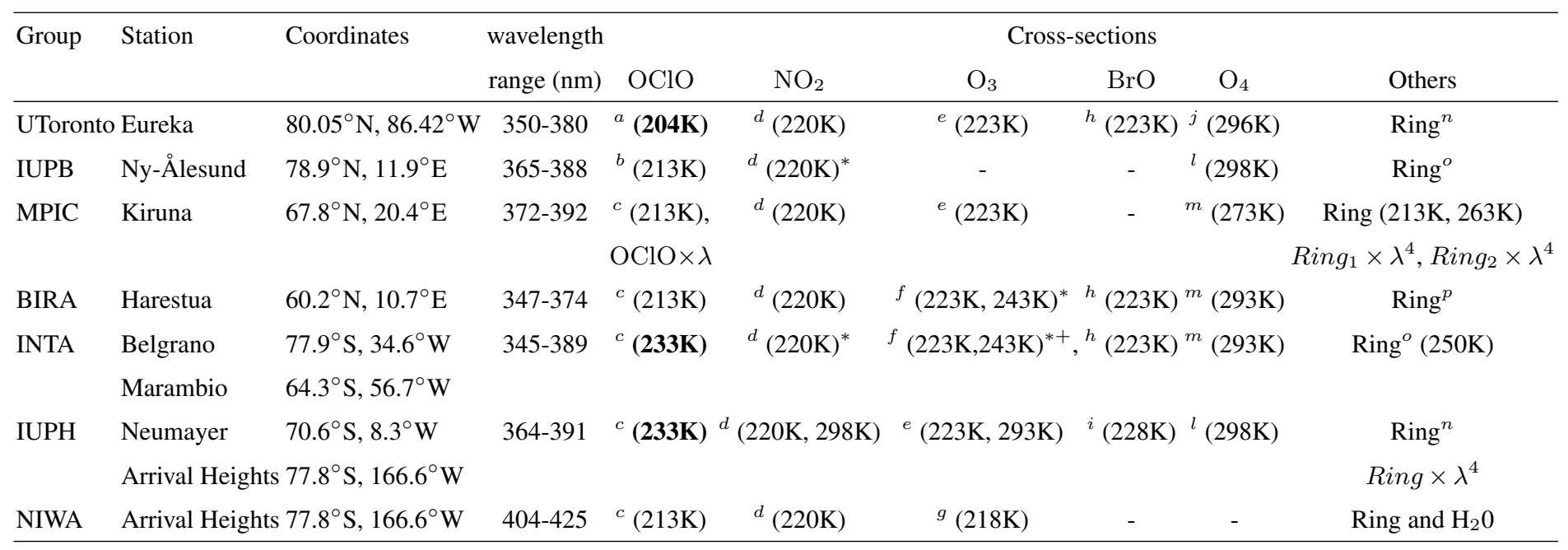

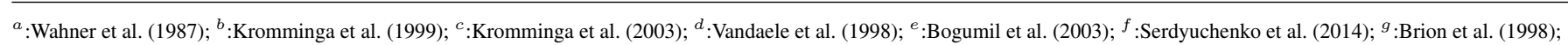

${ }^{h}$ :Fleischmann et al. (2004); ${ }^{i}$ :Wilmouth et al. (1999); ${ }^{j}$ :Greenblatt et al. (1990); ${ }^{k}$ :Hermans et al. (2003); ${ }^{l}$ :Hermans et al. (1999); ${ }^{m}$ :Thalman and Volkamer (2013);

${ }^{n}:$ Chance and Spurr (1997); ${ }^{o}:$ QDOAS high resolution based on SAO: Chance and Kurucz (2010); ${ }^{p}:$ SCIATRAN

${ }^{*}$ : I0 correction (Aliwell et al., 2002); ${ }^{+}$: with Puḳite et al. (2010) approach

are necessarily needed especially when a small wavelength interval is considered. E.g., the Ny-Ålesund IUPB analysis (365$388 \mathrm{~nm}$ ) does not include $\mathrm{O}_{3}$ and $\mathrm{BrO}$ while the Kiruna MPIC analysis (372-392nm) does not include BrO. For the NIWA visible interval these 2 gases are also not necessary, while the water vapor cross-section should be considered.

In order to assess the uncertainties related to the use of different OClO DOAS fit settings by the different groups, we performed a series of sensitivity tests that are reported in the next subsection.

\subsubsection{SCD error estimation}

In this section we summarize the ground-based SCD error estimation. The random component of the uncertainty is evaluated using results from DOAS retrievals performed by each group, and, for the systematic uncertainty, we perform sensitivity tests to evaluate the impact of applying different retrieval settings, as presented in Table 2 . The details of the different sensitivity tests are presented in Annex A2, and the results are summarized here and in the different tables.

\section{Random errors:}

Random errors on SCDs are estimated by each group as part of their DOAS analysis. As summarized in Table 3, median values for the different datasets range from 6 to $22 \%$ for SCD values of about $15 \pm 2 \times 10^{13} \mathrm{molec} / \mathrm{cm}^{2}$ (representative of OClO measurements in activated conditions and median values of the SZA in between $86^{\circ}$ to $90^{\circ}$, depending on the station). These values are globally consistent with past literature estimations (about $2 \times 10^{13} \mathrm{molec} / \mathrm{cm}^{2}$ for Neumayer and Arrival Heights 
(Frieß et al., 2005), 4-10\% at $90^{\circ}$ SZA for the NIWA Arrival Heights (Kreher et al., 1996) and $20 \%$ for Ny-Ålesund data at $90^{\circ}$ SZA (Oetjen et al., 2011)).

\section{Systematic errors:}

Systematic errors on OClO SCDs are estimated based on sensitivity tests performed using spectra recorded with the IUPB instrument in Ny-Ålesund during of a few days in February 2014. As presented in Annex A2, we investigated the impact of main differences that can be identified in Table 2, i.e, first, the choice of the OClO cross-sections source and its temperature, and secondly the different wavelength ranges.

The estimated systematic errors range between 2 and $15 \%$ for the uncertainty related to the OClO cross-section (see Fig. A1) and a total uncertainty of about $17 \%$ (Table A2). The values corresponding to each group's choice are indicated in the first column of the systematic uncertainty contributions in Table 3.

The errors due to the different group's retrieval choices are estimated through regression analysis of each setting with respect to the median OClO SCD values (see Fig. A2). The results present compact regression with RMS generally smaller than $2 \times 10^{13} \mathrm{molec} / \mathrm{cm}^{2}$, except for IUPH and MPIC. As discussed in Annex A2, results for the latter two cases are likely biased due to the limited wavelength range (up to about 390.4nm) of the Ny-Ålesund spectra. All intercepts except for IUPH are smaller than $1 \times 10^{13} \mathrm{molec} / \mathrm{cm}^{2}$ (see Fig. A2), meaning that the observed bias is mostly multiplicative. The values corresponding to each group's choice are indicated in the second column of the systematic uncertainty contributions in Table 3. The largest impact on the slope is obtained for the MPIC and for UToronto cases, leading to a difference between all cases of about $18.5 \%$ (see Table A2). This value is considered as the maximum systematic uncertainty on the retrieval choice for the systematic uncertainty contribution in Table A2, leading to a total maximum systematic uncertainty of about $25 \%$ when adding the contribution related to the $\mathrm{OClO}$ cross-section source.

\section{Expected systematic bias against GOME-2:}

The expected systematic bias due to differences between each group's analysis and the GOME-2 OCIO retrieval settings is investigated in a third test where the median OClO SCDs are replaced by the SCDs obtained using the GOME-2 settings in the scatter plots (see Fig. A3). For each group, the total expected systematic bias on OClO SCD consists of a first component due to the difference in the used OClO cross-section compared to Kromminga et al. (2003) (reported as the first number of the last column of Table 3) and a second component coming from the impact of other settings, as obtained in Fig. A3. The total expected systematic bias on OClO SCDs with respect to GOME- 2 analysis ranges between $4 \%$ and $16 \%$ for the different stations.

\subsubsection{SCD offset correction}

Although OClO SCD measurements used in this study are obtained using a fixed reference spectrum selected outside of the activated period to make sure that no residual OClO is contained in this reference, OClO SCD offsets are often observed in actual measurements due to instrumental effects leading to systematic spectral interferences with OClO absorption structures 
Table 3. Error estimates for the different $\mathrm{OClO}$ analysis at each station, in percent. The random uncertainty is estimated from the DOAS fit uncertainty for an OClO SCD of $15 \pm 2 \times 10^{13} \mathrm{molec} / \mathrm{cm}^{2}$. The systematic uncertainty is evaluated considering the impact of using different OClO cross-sections as well as different retrieval settings (see text and Fig. A1, A2, Table A2). The total uncertainty is calculated as the quadrature sum of random and systematic contributions. Estimation of the expected systematic bias with respect to the GOME-2 analysis setting is given in the last column (see text and Fig. A3).

\begin{tabular}{|c|c|c|c|c|}
\hline \multirow[b]{2}{*}{ Stations } & \multicolumn{3}{|c|}{ Uncertainties [\%] } & \multirow{2}{*}{\begin{tabular}{|c} 
Syst. Biases [\%] \\
wrt GOME-2 \\
(OClO xs; others choices: Tot)
\end{tabular}} \\
\hline & $\begin{array}{l}\text { Rand. } \\
\text { DOAS fit }\end{array}$ & Syst. & Total & \\
\hline Belgrano & 13 & $2 ; 0.2$ & 13.1 & $2 ; 5: 5.4$ \\
\hline $\begin{array}{l}\text { Arrival Heights } \\
\text { (NIWA) }\end{array}$ & 22 & $-;$ n.a. & n.a. & -; n.a.: n.a. \\
\hline Arrival Heights & 15 & $2 ; 11$ & 18.7 & $2 ; 3: 3.6$ \\
\hline Neumayer & 14 & $2 ; 11$ & 17.9 & $2 ; 3: 3.6$ \\
\hline Marambio & 13 & $2 ; 0.2$ & 13.1 & $2 ; 5: 5.4$ \\
\hline Harestua & 6.5 & $-; 4.5$ & 7.9 & -;9: 9 \\
\hline Kiruna & 22 & $-; 7.5$ & 23.2 & -; 16: 16 \\
\hline Ny-Ålesund & 10 & $2.5 ; 2.5$ & 10.7 & $2.5 ; 8: 8.4$ \\
\hline Eureka & 10 & $15 ; 4$ & 18.5 & 15;1.3: 15.1 \\
\hline
\end{tabular}

(e.g. thermal instabilities leading to changes in instrumental spectral response) or due to possible unknown atmospheric effects interfering with the $\mathrm{OClO}$ retrieval.

Such effects generally lead a systematic bias on the retrieved OClO SCDs that can vary in time, but usually with a time constant that exceeds the duration of a twilight period.

To further mitigate the impact of such biases, an empirical correction was designed and systematically applied to the groundbased data sets.

The principle of this correction relies on the assumption that $\mathrm{OClO}$ bias sources are constant during a twilight period and therefore lead to an offset on the retrieved OClO SCDs. For each morning and evening twilight, we draw a Langley plot, i.e. a plot of the SCDs reported as a function of the OClO air mass factor (AMF). One example of such a plot is represented in Fig. 5, for the Harestua station on 13 January 2013. The AMF used for this purpose was empirically estimated from observed OClO SCDs recorded during a series of chlorine activation events of various strengths (see Fig. 6). The AMF is here defined as the ratio of the measured slant column to the vertical column estimated at $70^{\circ}$ of SZA, assuming that at this solar elevation a simple geometrical AMF can be used. The grey area in Fig. 6 indicates the range of the measured OClO AMFs, while the blue and green curves show AMFs calculated using the DISORT radiative transfer model coupled PSC-Box and initialized with SLIMCAT 3D-Chemical transport model simulations, as explained in Hendrick et al. (2007). The red line represents the median value of the measured AMFs, which was used an input for the present analysis. 
As can be seen in Fig. 5, a linear relationship is obtained between the empirical AMFs and the measured SCDs over a large range of SZA values. We also note that although the reference spectrum used to analyse these data was recorded well outside the activated period (in late April in this case) and therefore does not contain any sizeable OClO amount, the observed SCDs present an offset, i.e. the measured SCDs do not converge to zero for low AMF values. This offset is necessarily an artefact and should be removed to restore physically consistent SCD values.

It must be noted here that this approach is only applicable for observations covering a sufficiently large range of SZAs. The limit on the minimum solar zenith angle has been empirically set to $86^{\circ}$. For high latitude observations during polar night conditions, when the SZA constantly exceeds $86^{\circ}$, an estimate of the offset was obtained by fitting a polynomial function to offsets derived during the illuminated periods.

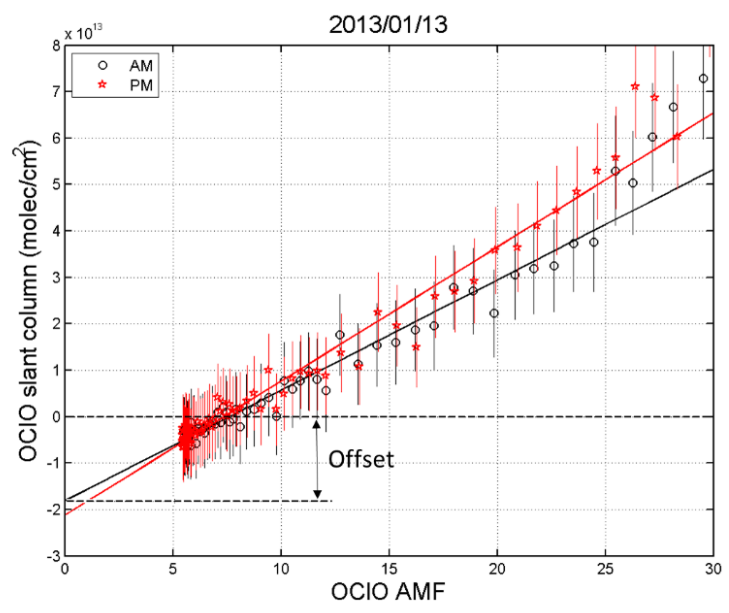

Figure 5. Illustration of the Langley plot method used to estimate offset artefacts on OClO SCD measurements. This case was obtained in Harestua on 13 January 2013.

Despite its empirical nature, this offset correction, which was derived independently for morning and evening data on each day, can be considered as objective as a) it is not linked to the satellite data and b) it is not based on subjective criteria such as the smoothness of the $\mathrm{OClO}$ timeseries.

This correction was applied to all ground-based datasets used in this study, except for NIWA measurements in Arrival Heights. At this site the method could not be used due to the unavailability of daily sequences of OClO measurements covering a suitable range of SZAs.

Figure 7 presents an illustration of the impact of the correction for the Neumayer ground-based dataset time-series. The original data is displayed in light grey and the corrected one in black. The same data set is also represented as a function of the SZA in the lower panel. As can be seen, in this case, the main impact of the offset correction is to reduce the apparent noise on the low values of the OClO SCD. During periods of strong activations, changes are generally minor. 
https://doi.org/10.5194/amt-2021-356

Preprint. Discussion started: 29 November 2021

(c) Author(s) 2021. CC BY 4.0 License.

(c) (i)
Atmospheric

Measurement

Techniques

Discussions

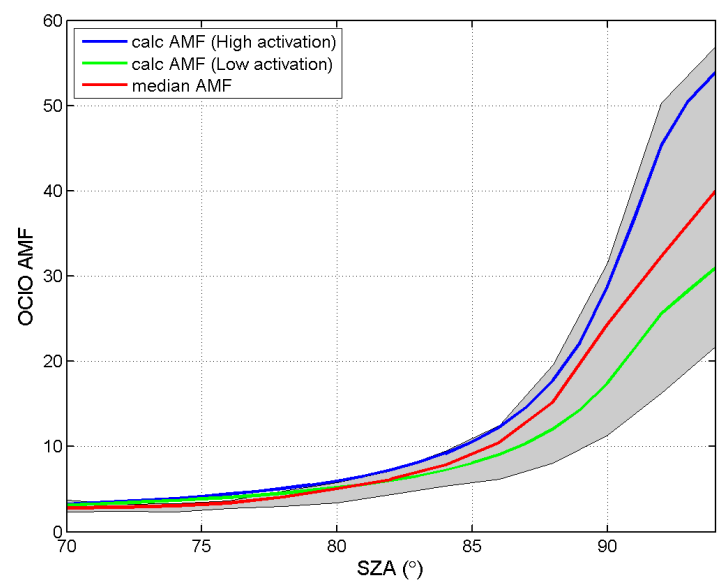

Figure 6. Illustration of the AMFs used for the Langley plots. The grey area indicates the range of the measured OClO AMFs, the red curve their median value, while the blue and green curves are AMFs calculated using the DISORT radiative transfer model coupled PSC-Box and initialized with SLIMCAT 3D-Chemical transport model simulations.
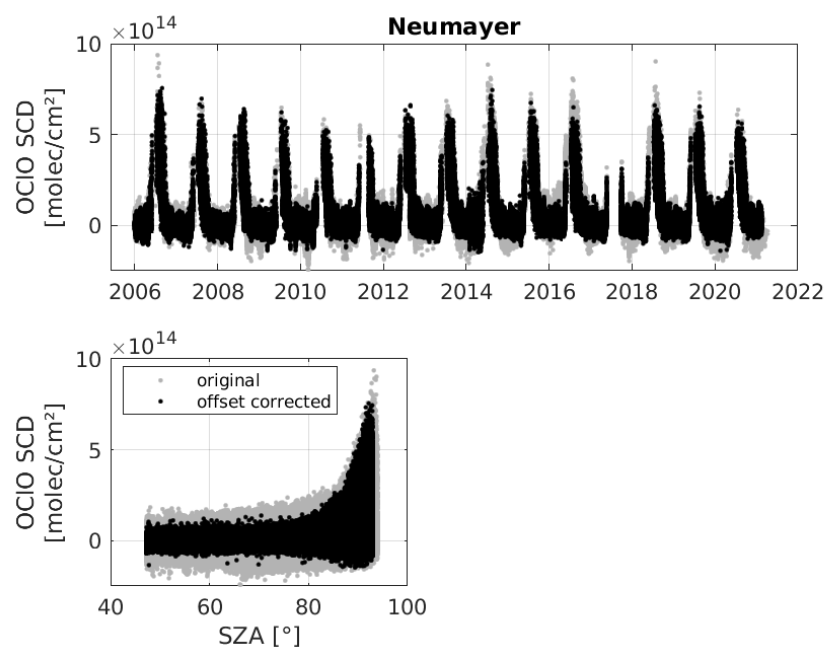

Figure 7. Illustration of the offsset correction impact on of Neumayer data (a) the time-series and (b) the SZA dependence.

\subsection{Comparison method}

For the comparison of GOME-2 and ZSL-DOAS data, a method similar to Richter et al. (2015) and Oetjen et al. (2011) was adopted. The GOME-2 GDP 4.8 OClO SCD data are extracted within $200 \mathrm{~km}$ of the different stations listed in Table 2. The mean value of the valid OClO SCD (oclo_flag value set to 1 or 2, i.e. between $85^{\circ}$ and $92^{\circ}$ SZA, Valks et al. (2019a, b)) is then 
calculated for each day, in order to improve the signal to noise ratio. Coincidences are obtained by selecting ground-based data that are within $\pm 1^{\circ} \mathrm{SZA}$ of the mean daily satellite value. Error weighted averages are performed using provided ground-based and satellite errors.

Comparisons of the daily coincidences are performed at each station for the whole available time-series. It should be noted that there is a non-constant number of points at $\mathrm{SZA}>85^{\circ}$ throughout the year at some stations. This is even more the case after the reduced swath configuration was adopted for GOME-2A in July 2013. During several periods of the year (depending on the location) no valid OClO SCD can be found and such periods tend to be longer after 2013.

The approach of comparing slant columns (instead of vertical columns) relies on the assumption that satellite nadir and ground-based zenith sky light paths are comparable at large SZA (Oetjen et al., 2011). In other words, satellite AMFs (AMFsat_nadir) and ground-based AMFs (AMFgb_zenith) are assumed to be similar. Oetjen et al. (2011) et al. calculated differences of up to $4 \%$ for the two observation geometries between $89^{\circ}$ and $91^{\circ} \mathrm{SZA}$ and of $13 \%$ at $80^{\circ} \mathrm{SZA}$ in Ny-Ålesund.
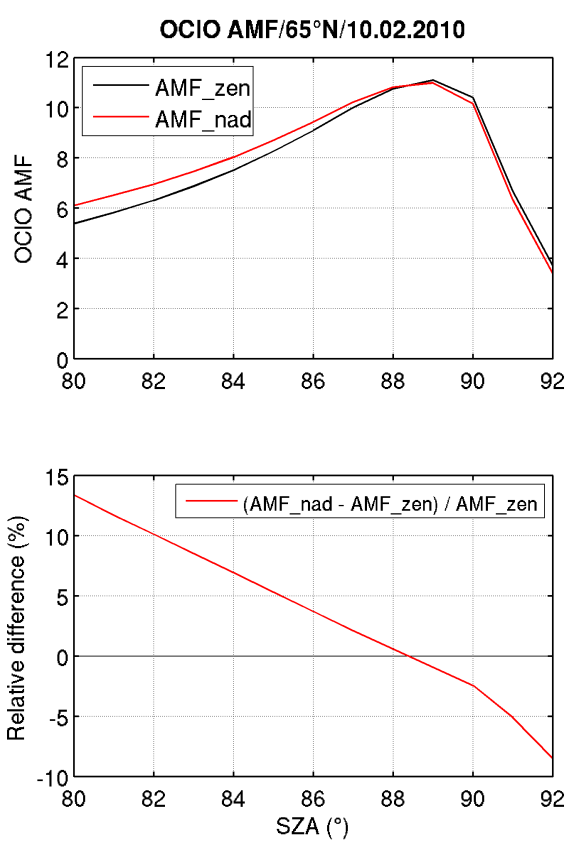

Figure 8. OClO AMF calculations for $65^{\circ} \mathrm{N}$ from ground-based zenith and satellite nadir geometries. shown in Figure 8. The simulations were performed using an implementation of the DISORT radiative transfer code accounting for the impact of photochemical enhancements along the light path at twilight (Hendrick et al., 2007). They confirm the Oetjen et al. (2011) results, with differences of up to $13 \%$ for SZA between 80 and $88^{\circ}$, and differences of up to $-8 \%$ between 88.5 and $92^{\circ} \mathrm{SZA}$. On average, over the $85^{\circ}$ to $92^{\circ}$ SZA range, the AMF difference is close to zero. 


\section{Comparison results}

Figures 9 to 14 present respectively the time-series of the GOME-2A (2007-2016) and GOME-2B (2013-2016) together with ground-based OClO SCDs measurements performed in each hemisphere. As expected, the data from the four Antarctic stations (Fig. 9 and 10) show a stronger OClO signal in the winter months, with values up to $50-100 \times 10^{13} \mathrm{molec} / \mathrm{cm}^{2}$, when the stations are under the influence of the polar vortex.

The presence of larger OClO columns in the austral winter and spring compared to the Northern Hemisphere was highlighted in past satellite's studies (Wagner et al., 2001, 2002; Wittrock et al., 1999). Above the Antarctic, high OClO SCDs are usually observed after mid May, with a large increase within a few days, reaching a maximum by mid-September and then quickly decreasing until the chlorine activation stops by late October (Wagner et al., 2001; Richter et al., 2005). Due to a less stable polar vortex, the year-to-year variability of $\mathrm{OClO}$ is large in the Northern Hemisphere, so that only few years are characterised by large activation events (Richter et al., 2005). The yearly variability in OClO SCD is anti-correlated with the temperature variations and modulated by PSC formation (Weber et al., 2003).

\subsection{Antarctic}

Figure 9 presents the daily comparisons between GOME-2A and ground-based data at the four Antarctic stations. At the Neumayer station, the ground-based OClO SCDs are available for the complete period of GOME-2A observations (20072016) showing enhanced OClO signals between August and October, when the polar vortex is above the station. In Arrival Heights, comparisons during the activated periods are missing for two years (2008 and 2014) in the IUPH dataset but are covered by the NIWA measurements, while in Belgrano four years of data outside of the polar night period (mid April to end of August) are available for the GOME-2 comparisons and in Marambio only one year (2015). When ground-based data are not available, the satellite daily mean overpass are displayed in light red. Figure 10 similarly presents the time-series of the GOME-2B comparisons for 2013-2016.

Each year an enhanced OClO signal (from 20 and up to 40 and $60 \times 10^{13} \mathrm{molec} / \mathrm{cm}^{2}$ ) is observed in August and September, followed by a decrease. The largest OClO columns are measured at Arrival Heights in 2012, 2013, 2015, at Neumayer in 2013, 2014, 2015 and at Belgrano in 2011, 2014 and 2015. There is some variability in the strength of the signal from year to year, but the daily variations are sampled in a coherent way from the ground and from space, with a general tendency for smaller (sometimes negative, especially for GOME-2A) OClO SCDs retrieved by the satellites during November to April, outside of the chlorine activation period.

A gap in the GOME-2A data is observed in October at the Neumayer station since 2013, due to the reduced swath of the satellite instrument. There are no satellite measurements within $200 \mathrm{~km}$ for both sensors between May and end of July, which results in missing the start of the chlorine activation. Some more pronounced negative slant columns appear in the GOME2A dataset after mid 2011, probably related to the degradation of the instrument. A quantitative comparisons for different GOME-2A periods is also shown in Fig. 15 and discussed later on. 

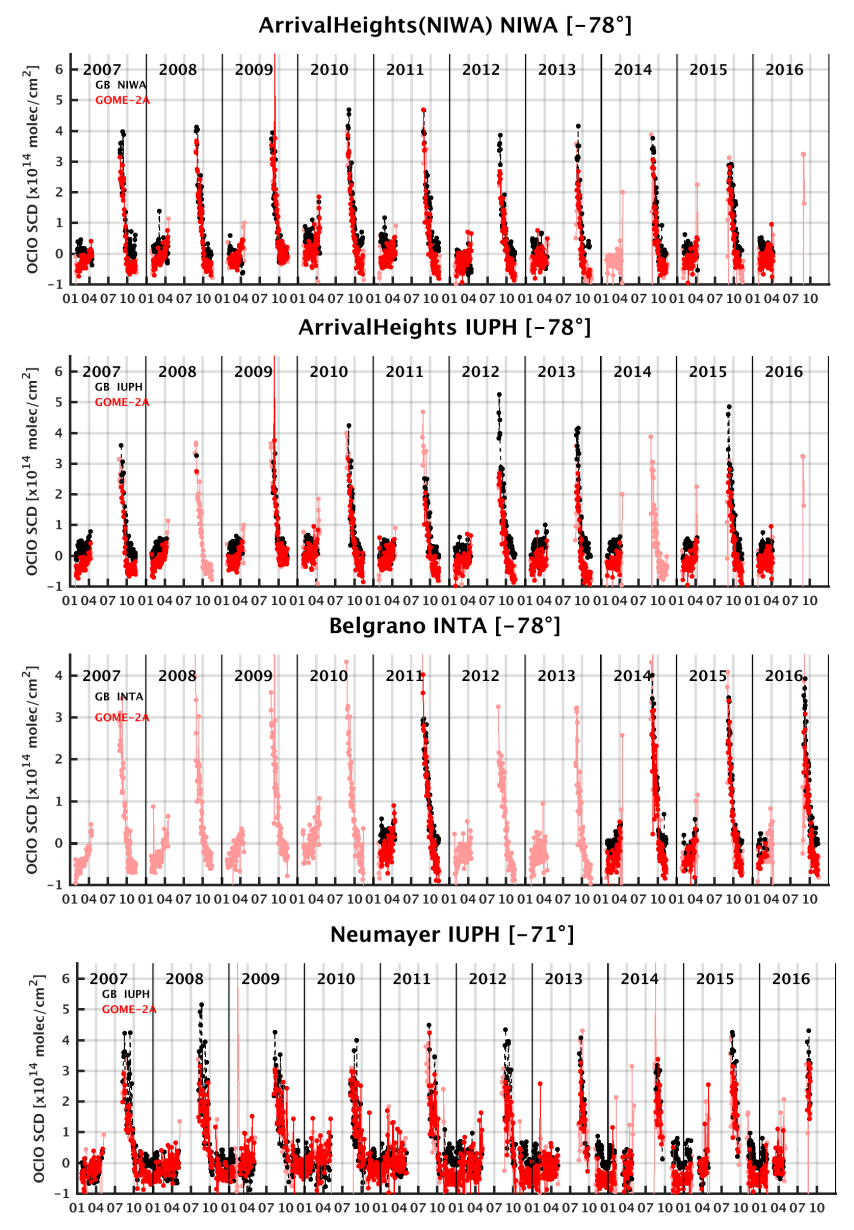

Marambio INTA [-64 $\left.{ }^{\circ}\right]$

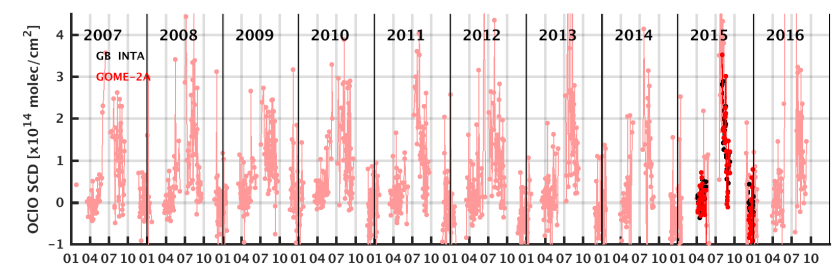

Figure 9. Time series of GOME-2A (red) OClO daily mean slant column data co-located with ground-based (black) measurements performed at each Antarctic station. Lighter/transparent red color is used for GOME-2A when there is no ground-based measurements.

In Marambio, an enhanced OClO signal is observed in June, August and September, with a data gap in July. A day-to-day variability of several $10 \times 10^{13} \mathrm{molec} / \mathrm{cm}^{2}$ is visible in GOME-2B data (Figure 10) during the activated period. This behaviour is related to the intermittent probing of air masses that are on the edge of the Antarctic polar vortex. The ground-based data 

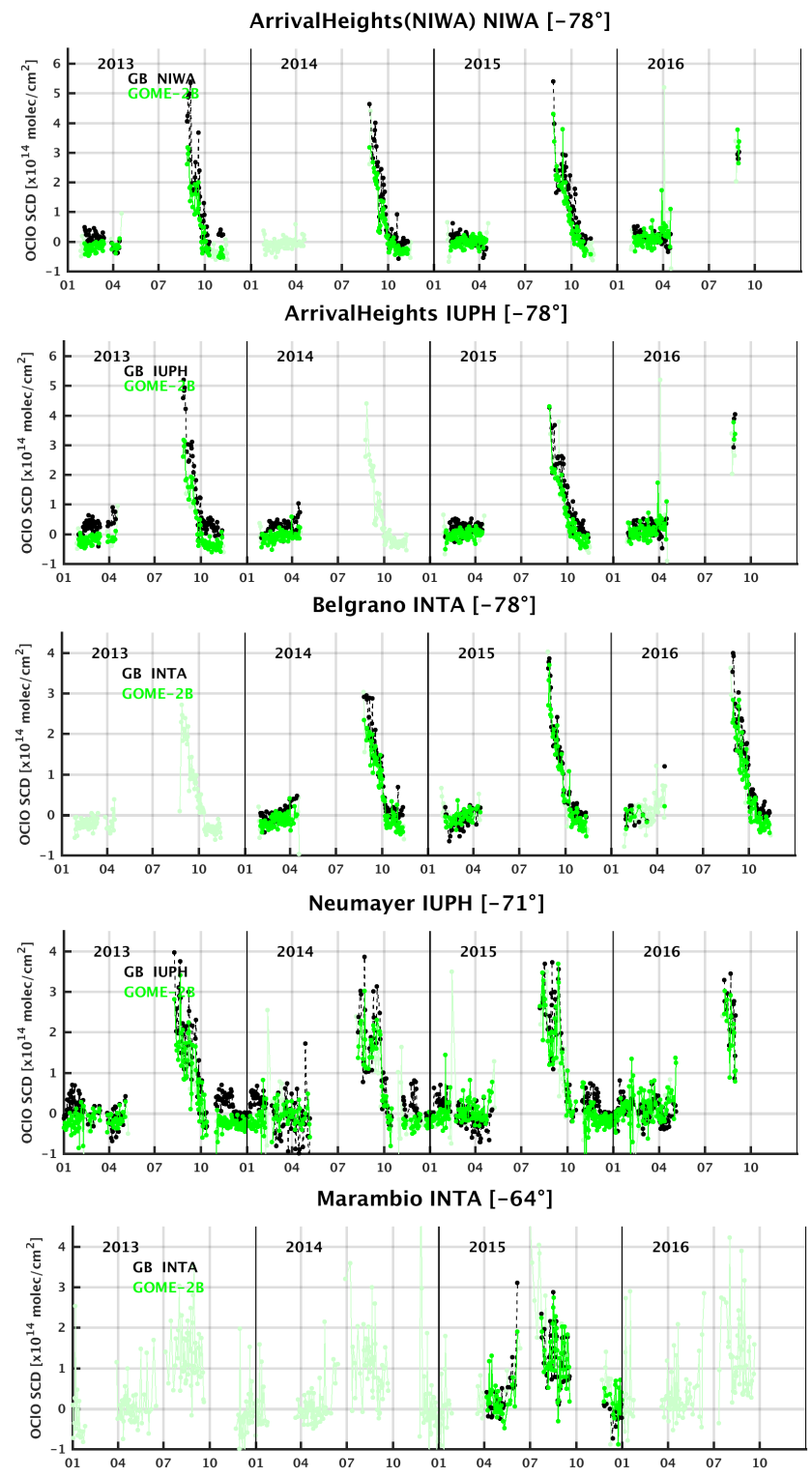

Figure 10. Time series of GOME-2B (green) $\mathrm{OClO}$ daily mean slant column data co-located with ground-based (black) measurements performed at each Antarctic station. Lighter/transparent green color is used for GOME-2B when there is no ground-based measurements.

seem more sensitive to these rapid changes, resulting in higher peaks than observed with GOME-2A and GOME-2B. For this station, the averaging of the satellite data within $200 \mathrm{~km}$ could mix air from inside and outside the vortex. Tests with a smaller co-location radius were performed for this station, but with similar results and less co-located points. 
https://doi.org/10.5194/amt-2021-356

Preprint. Discussion started: 29 November 2021

(c) Author(s) 2021. CC BY 4.0 License.

(c) (i)

\section{Atmospheric \\ Measurement \\ Techniques \\ Discussions}

The statistical analysis (presented in Fig. 11 and Fig. 12) leads to correlation coefficients from 0.77 (Neumayer) to 0.92 (Belgrano) for GOME-2A and from 0.84 to 0.95 for GOME-2B daily comparisons, with linear regression slopes in the range of 0.72-1.06 and 0.71-0.84 for GOME-2A and GOME-2B, respectively.
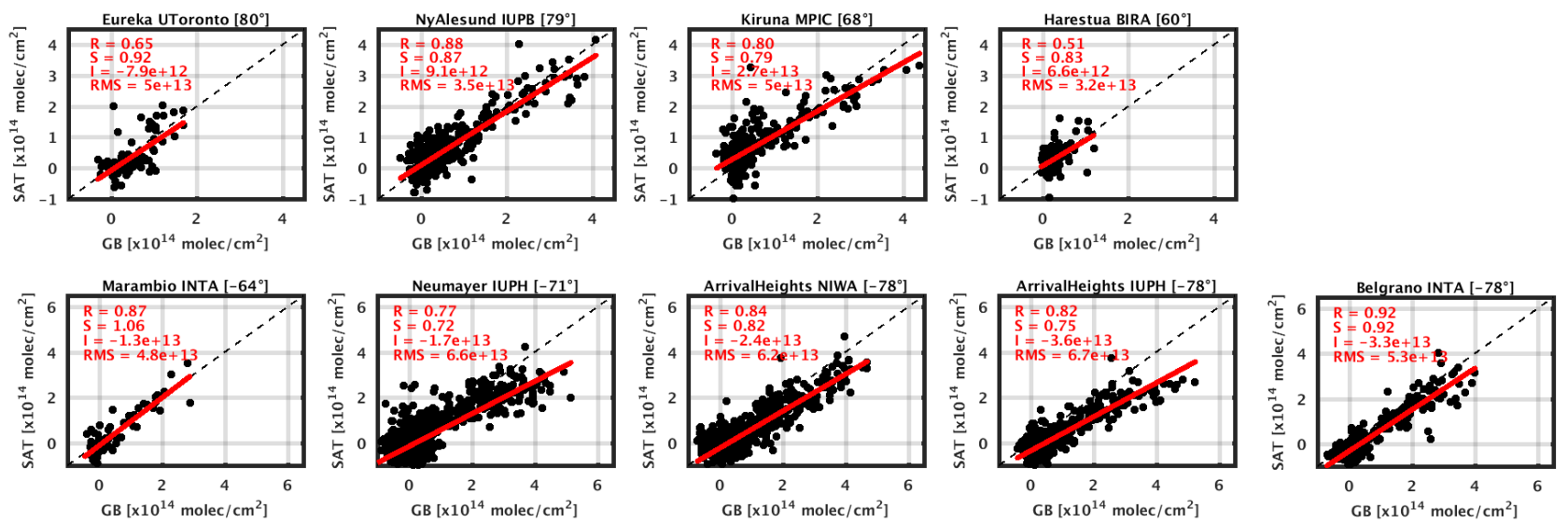

Figure 11. Scatter plot of GOME-2A OClO slant column data co-located with ground-based measurements at each station.
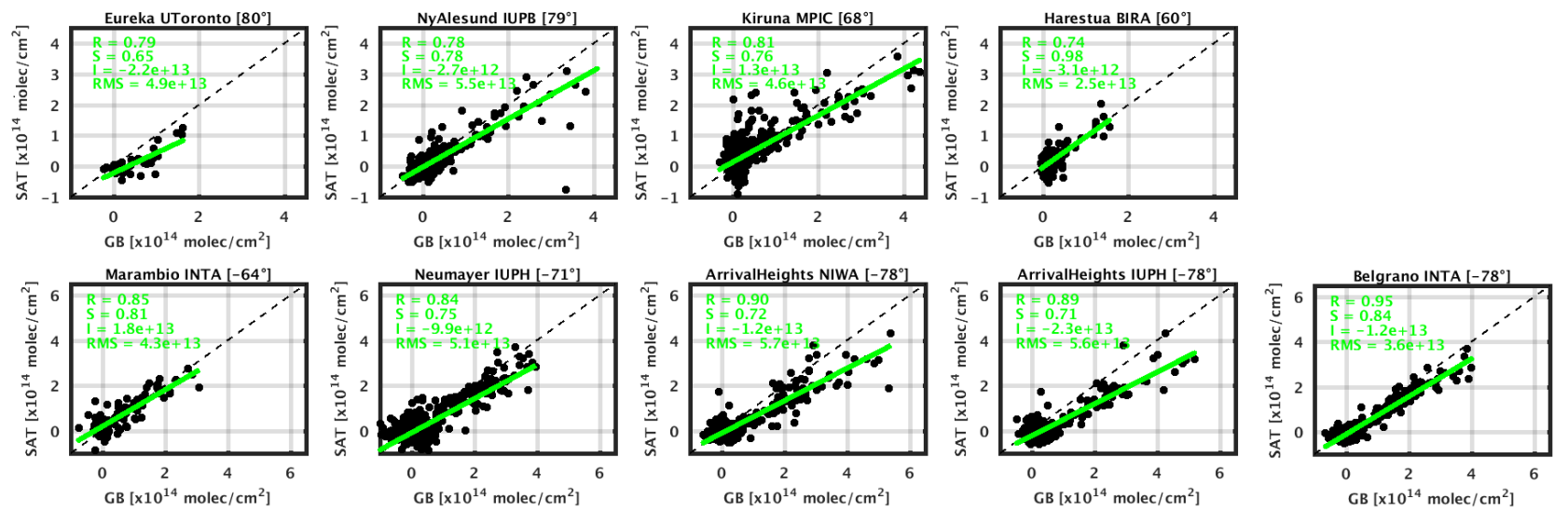

Figure 12. Scatter plot of GOME-2B OClO slant column data co-located with ground-based measurements at each station. 


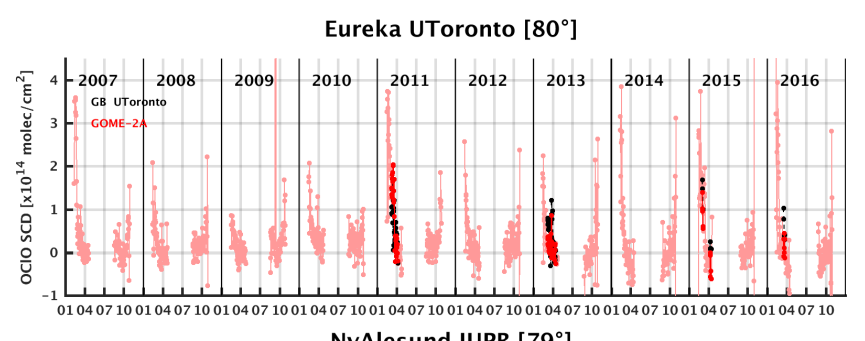

NyAlesund IUPB $\left[79^{\circ}\right]$

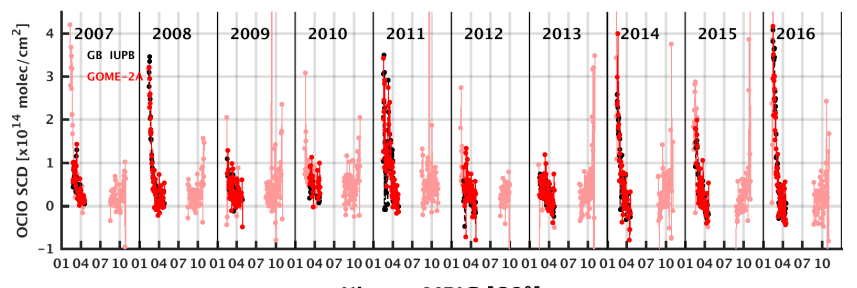

Kiruna MPIC $\left[68^{\circ}\right]$

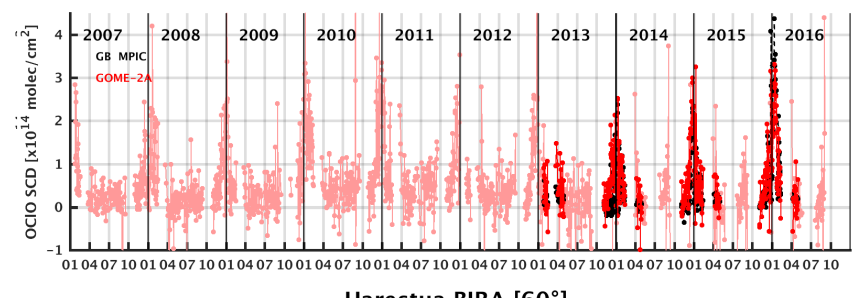

Harestua BIRA [60 $\left.{ }^{\circ}\right]$

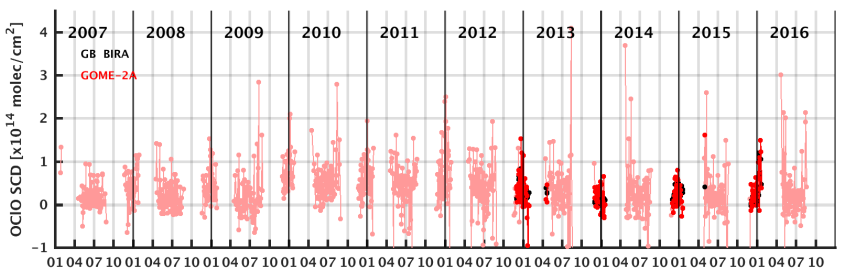

Figure 13. Time series of GOME-2A (red) OClO daily mean slant column data co-located with ground-based (black) measurements performed at each Arctic station. Lighter/transparent red color is used for GOME-2A when there is no ground-based measurements.

\subsection{Arctic}

Comparisons at the four Arctic stations are shown in Fig. 13 and 14. It should be noted that Eureka and Ny-Ålesund are in the polar night until about February/March, so that ground-based measurements can be done only up to April/May. After that period, SZAs are too low (smaller than $88^{\circ}$ ) to perform ground-based measurements of OClO.

At all stations GOME-2A, GOME-2B and the zenith-sky DOAS instruments capture similarly the seasonal cycle of the OClO $\mathrm{SCD}$, as well as its day-to-day variations. Differences from year to year and station to station exist, but typically enhanced OClO slant columns are found at the four sites between October and March, with large values in 2007, 2008, 2011, 2014, 2015, 2016 and values up to $40 \times 10^{13} \mathrm{molec} / \mathrm{cm}^{2}$, as in Ny-Ålesund and Kiruna during the 2015-2016 winter. 

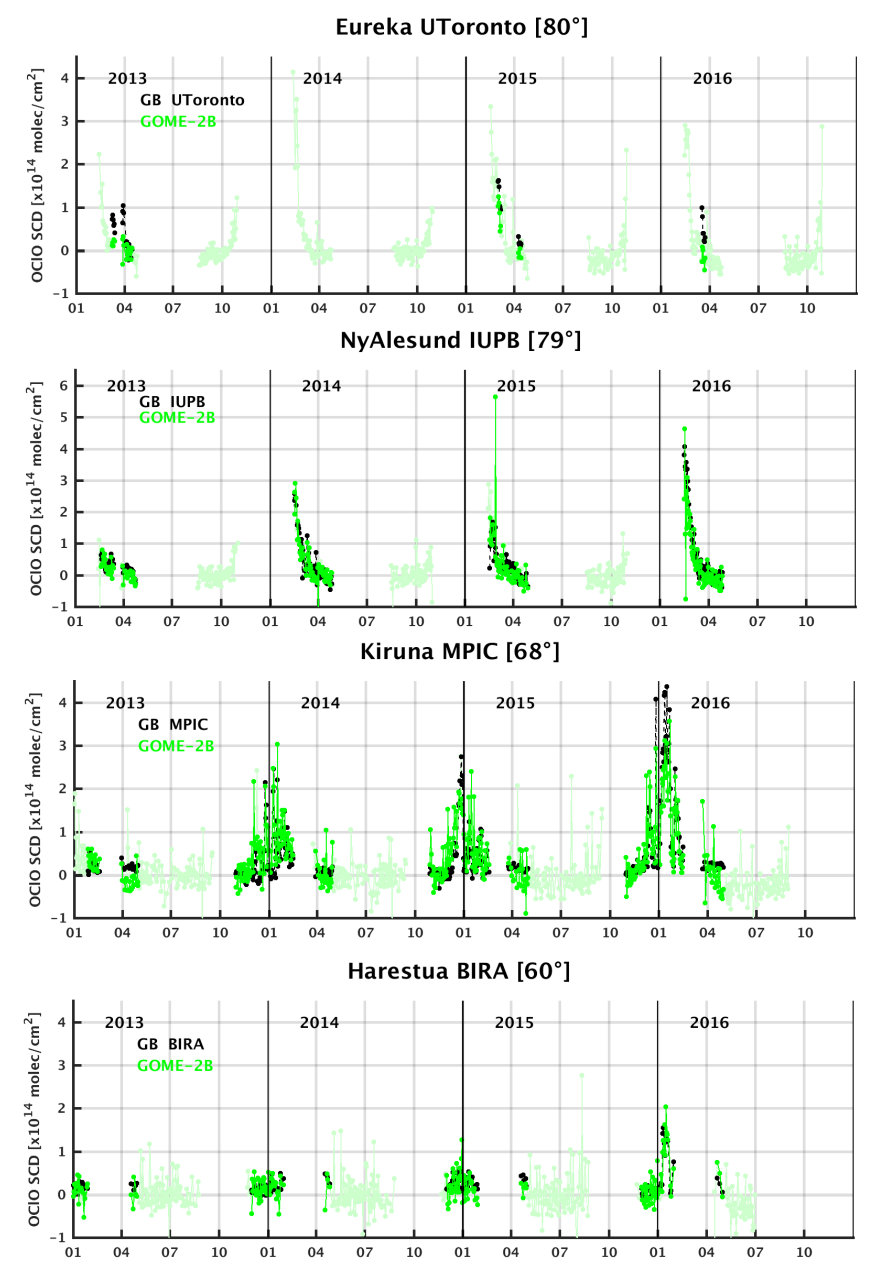

Figure 14. Time series of GOME-2B (green) OClO daily mean slant column data co-located with ground-based (black) measurements performed at each Arctic station. Lighter/transparent green color is used for GOME-2B when there is no ground-based measurements.

For Ny-Ålesund and Kiruna, years 2014, 2015 and 2016 show an enhanced OClO signal (with peaks larger than 20-30 x10 13 molec $/ \mathrm{cm}^{2}$ ) while 2013 does not seem to show any chlorine activation. Unlike Ny-Ålesund and Kiruna, the chlorine activation in 2014 and 2015 cannot be seen in Harestua, probably due to the lack of polar vortex excursions at latitudes as low as as $60^{\circ}$. In 2016, on the other hand, a clear enhancement is visible from the ground and from GOME-2A and GOME-2B in January (with a peak $13-15 \times 10^{13} \mathrm{molec} / \mathrm{cm}^{2}$ ). Unfortunately the gap in the GOME-2 data from February to May (related to the GOME-2 pixels SZA being smaller than $85^{\circ}$ ) prevents to detect the other OClO SCD peaks seen by the ground-based instrument.

The large OClO peak in early 2008 can be understood by the very cold stratospheric temperatures in the winter 2007/2008. According to Kuttippurath et al. (2009), the temperature started to decrease in November 2007 and remained low until a major 
stratospheric warming in late February 2008. At this time, temperatures were below the PSC formation threshold inside the polar vortex. According to Tétard et al. (2009), in January 2008, the polar vortex was not centered on the geographical north pole, and was gradually moving towards Europe. This would bring the vortex over Ny-Ålesund and allow to measure high OClO SCDs over this station.

GOME-2A is more noisy than GOME-2B, especially outside the chlorine activation period (e.g. negative points in January to April and after September in 2013 and in the following years), but both sensors follow nicely the enhanced OClO signals in winter periods. As for GOME-2A, the gap in the comparisons around February, March and part of April is related to the GOME-2B SZA being smaller than $85^{\circ}$ in that period, leading to the exclusion of these data (see Sect. 2).

Differences between GOME-2A and GOME-2B are related to the smaller GOME-2A swath after July 2013 and the 30 minutes difference between both instrument's. Moreover, the GOME-2A degradation and the possible different impact of the mean residual, the scan angle empirical correction functions and the additional offset correction as discussed in Sect. 2 could also play a role in enhancing the noise of GOME-2A OClO columns in comparisons to GOME-2B.

An illustration of this time-degradation effect is given in Figure 15. On the left panel all the Neumayer data are presented while, on the right panel, only the first 4 years are displayed for each instrument (2007-2011 and 2013-2016). RMS values given below the figures clearly demonstrate that during their first 4 years of operation, both GOME-2A and GOME-2B had a similar level of noise.

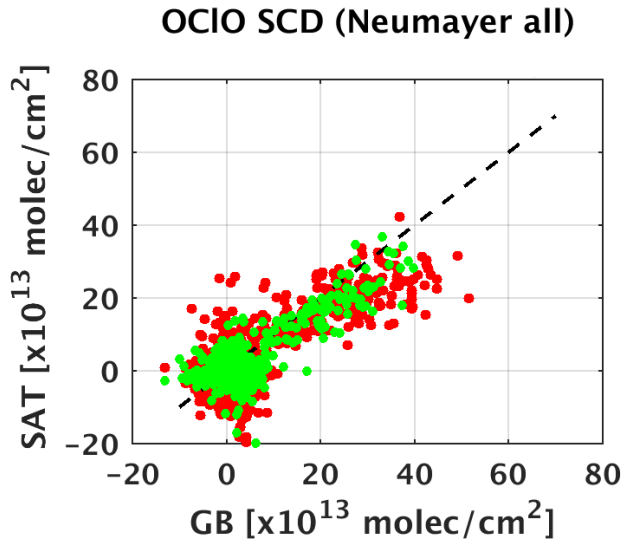

$$
\begin{array}{ll}
\text { GOME-2A (\#1536) } & \text { GOME-2B }(\# 633) \\
R=0.77, S=0.72 & R=0.84, S=0.75 \\
\text { Offset }=-1.7 e+13 & \text { Offset }=-9.9 e+1 \\
\text { RMS }=6.6 e+13 & \text { RMS }=5.1 e+13
\end{array}
$$

OCIO SCD (Neumayer first 4 years)

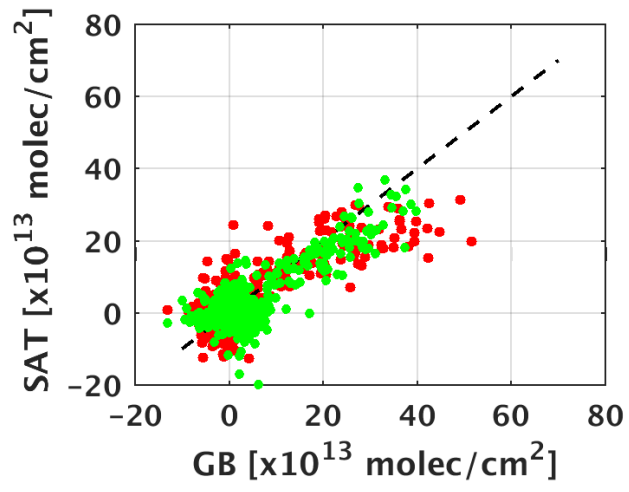

$$
\begin{array}{ll}
\text { GOME-2A (\#698) } & \text { GOME-2B }(\# 633) \\
\mathbf{R}=0.8, S=0.69 & \mathrm{R}=0.84, \mathrm{~S}=0.75 \\
\text { Offset }=-2 \mathrm{e}+\mathbf{1 2} & \text { Offset }=-9.9 \mathrm{e}+12 \\
\mathrm{RMS}=5.7 \mathrm{e}+\mathbf{1 3} & \mathrm{RMS}=5.1 \mathrm{e}+13
\end{array}
$$

Figure 15. Scatter plot between daily GOME-2A (red) and GOME-2B (green) GDP 4.8 satellite data and ground-based data at Neumayer station for all data (left) and the first 4 years of operation (right) of each satellite. 
https://doi.org/10.5194/amt-2021-356

Preprint. Discussion started: 29 November 2021

(C) Author(s) 2021. CC BY 4.0 License.
Atmospheric

Measurement

Techniques

Discussions

The statistical analysis (presented in Fig. 11 and Fig. 12) leads to correlation coefficients from 0.51 (Harestua) to 0.88 (NyÅlesund) for GOME-2A and 0.74 to 0.81 for GOME-2B daily comparisons, with linear regression slopes around 0.79-0.92 and 0.65-0.98 for GOME-2A and GOME-2B respectively.

\subsection{Comparison summary}

We now consider all the stations and focus only on the activated periods (July-August-September in the Southern Hemisphere and January-February-March in the Northern Hemisphere). Figure 16 summarizes the biases between GOME-2 and groundbased ZSL-DOAS time-series using box-whisker plots of their differences at each site. Stations are ordered by latitude, from the Arctic (top) to the Antarctic (bottom). It is worth mentioning that although Eureka and Ny-Ålesund are close to each other in latitude $\left(80^{\circ} \mathrm{N}\right.$ and $\left.79^{\circ} \mathrm{N}\right)$, they are far away in longitude (Canada and northern Europe), which implies very different positions with respect to the polar vortex. This is also true for Arrival Heights and Belgrano, which are both at a latitude of $78^{\circ} \mathrm{S}$ but located at opposite sides of the Antarctic continent (see map in Figure 3). The figure indicates a general negative bias (up to around $-8 \times 10^{13} \mathrm{molec} / \mathrm{cm}^{2}$ ) for both GOME-2 instruments at most stations, except for Kiruna and Marambio. The differences between GOME-2A and GOME-2B are of a few $10^{13} \mathrm{molec} / \mathrm{cm}^{2}$. Differences of the same order of magnitude are found e.g., between the two Arrival Heights instruments. The median bias statistics of the individual comparisons are reported in Table 4 for each station and for both hemispheres, together with regression analysis statistics. In relative values, the station biases range from $-53 \%$ to $8 \%$ for GOME-2A and -78\% to 13\% for GOME-2B for Eureka and Marambio.

Table 4. Summary of the regression parameters and bias between GOME-2A and B and zenith-sky OClO SCDs daily mean comparisons for the active months (January-February-March for the Northerm Hemisphere and July-August-September for the Southern Hemisphere). Intercept, RMS and absolute biases (median (SAT-GB)) are in $\times 10^{13} \mathrm{molec} / \mathrm{cm}^{2}$.

\begin{tabular}{|c|c|c|c|c|c|c|c|c|c|c|c|c|}
\hline \multirow{3}{*}{ Station } & \multirow{3}{*}{ Period } & \multicolumn{5}{|c|}{ GOME-2A } & \multicolumn{6}{|c|}{ GOME-2B } \\
\hline & & \multirow[b]{2}{*}{$\mathrm{R}$} & \multicolumn{3}{|c|}{ Regression } & \multirow{2}{*}{$\begin{array}{c}\text { Bias } \\
\text { abs [rel] }\end{array}$} & \multirow[t]{2}{*}{ Period } & \multicolumn{4}{|c|}{ Regression } & \multirow{2}{*}{$\begin{array}{c}\text { Bias } \\
\text { abs [rel] }\end{array}$} \\
\hline & & & $S$ & I & RMS & & & $\mathrm{R}$ & S & I & RMS & \\
\hline Eureka & $2011-2016$ & 0.55 & 0.83 & 0.19 & 5.5 & $-2.8[-53 \%]$ & 2013-2016 & 0.86 & 0.99 & -5.5 & 6.1 & $-5.6[-78 \%]$ \\
\hline Ny-Ålesund & $2007-2016$ & 0.89 & 0.86 & 1.2 & 3.8 & $-0.05[3.2 \%]$ & 2013-2016 & 0.74 & 0.78 & -0.14 & 6.7 & $-1.9[-33 \%]$ \\
\hline Kiruna & $2013-2016$ & 0.85 & 0.76 & 2.6 & 4.8 & $0.2[0.09 \%]$ & 2013-2016 & 0.87 & 0.70 & 2.5 & 4.7 & $-0.12[-9 \%]$ \\
\hline Harestua & $2012-2016$ & 0.49 & 0.81 & -0.32 & 4.1 & $-0.6[-21 \%]$ & 2013-2016 & 0.87 & 1.04 & -0.61 & 2.26 & $-0.5[-21.5 \%]$ \\
\hline Marambio & 2015 & 0.86 & 1.01 & -0.1 & 4.6 & $0.9[8 \%]$ & 2015 & 0.88 & 0.89 & 1.8 & 3.44 & $1.1[13 \%]$ \\
\hline Neumayer & $2007-2016$ & 0.75 & 0.51 & 5.9 & 8.6 & $-3.5[-18 \%]$ & 2013-2016 & 0.85 & 0.76 & 0.82 & 6.2 & $-3.5[-20 \%]$ \\
\hline ArrivalHeights (NIWA) & $2007-2016$ & 0.74 & 0.77 & 0.29 & 8.9 & $-6.9[-36 \%]$ & 2013-2016 & 0.84 & 0.71 & -0.24 & 9.1 & $-6[-37 \%]$ \\
\hline ArrivalHeights (IUPH) & $2007-2016$ & 0.65 & 0.64 & -0.09 & 11.7 & $-8.3[-42 \%]$ & 2013-2016 & 0.89 & 0.74 & -2.5 & 10.3 & $-7.5[-40 \%]$ \\
\hline Belgrano & 2011;2014-2016 & 0.77 & 0.76 & 0.68 & 6.9 & $-3.5[-23 \%]$ & 2014-2016 & 0.91 & 0.76 & 1.03 & 4.96 & $-3.3[-19 \%]$ \\
\hline all stations/points & $2007-2016$ & 0.80 & 0.64 & 2 & 7.9 & $-2.3[-22.3 \%]$ & 2013-2016 & 0.87 & 0.73 & 0.9 & 6.3 & $-2.2[-24.4 \%]$ \\
\hline NH stations/points & $2007-2016$ & 0.85 & 0.85 & 1.1 & 4.3 & $-0.1[-5 \%]$ & 2013-2016 & 0.79 & 0.76 & 0.64 & 5.3 & $-1.1[-24 \%]$ \\
\hline SH stations/points & $2007-2016$ & 0.71 & 0.61 & 2.5 & 9.9 & $-5.5[-30 \%]$ & 2013-2016 & 0.84 & 0.70 & 1.3 & 7.25 & $-4.4[-24 \%]$ \\
\hline
\end{tabular}




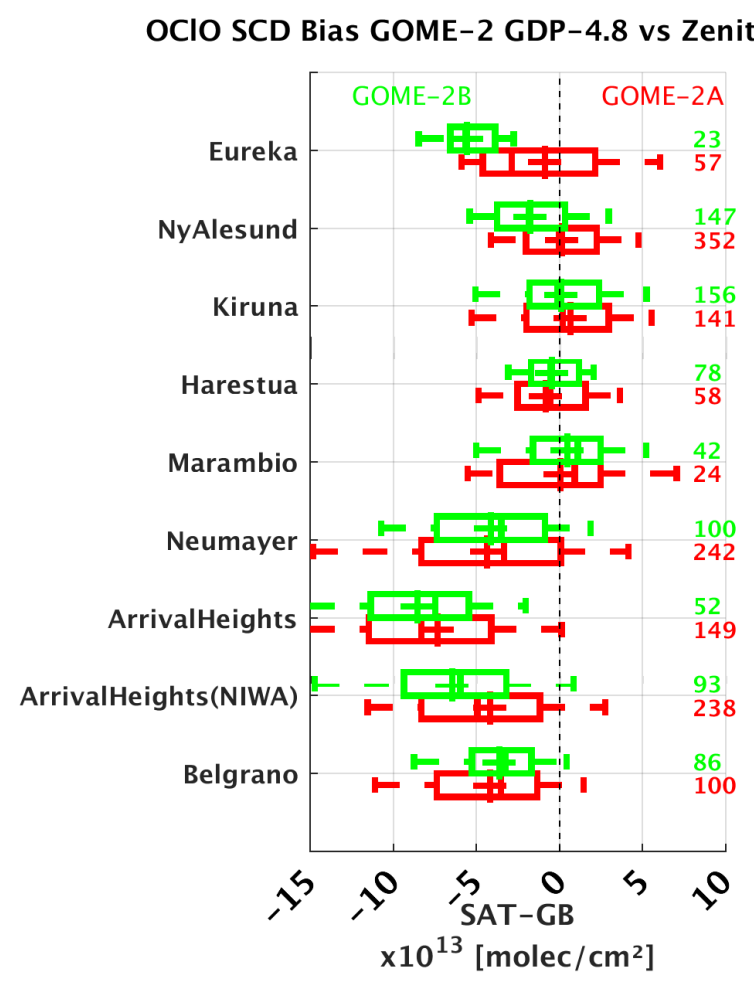

Figure 16. Box and whisker plot of the difference between all the GOME-2 and ZSL-DOAS OCIO SCD pairs during active period months. Stations are ordered by decreasing latitude (South at the bottom). The box and whisker plots are defined as follow: crosses and lines for the mean and median values, boxes for the 25th and 75th percentile and dashed lines for the 9th and 91st percentile. Numbers on the right correspond to the number of days considered in the analysis.

Figure 17 presents the results as a scatter plot, with GOME-2A values in red and GOME-2B values in green. It can be seen that GOME-2A results are slightly noisier than GOME-2B, with several outliers, a smaller correlation coefficient $(0.8$ wrt to 0.87 ) and larger RMS values. As already mentioned, this is likely related to instrumental degradation effects and/or the different empirical corrections used for GOME-2A. Regression slopes are about 0.64 for GOME-2A and 0.72 for GOME-2B, with an intercept of about $2 \times 10^{13} \mathrm{molec} / \mathrm{cm}^{2}$ for GOME-2A and half of it for GOME-2B. Fig. 18 presents the same data but color-coded according to the different stations.

340 Concentrating on the slopes of daily linear regressions at each station (Table 4), values around or better than 0.7 are found for GOME-2B, and often slightly smaller for GOME-2A. The intercepts are generally smaller than $2 \times 10^{13} \mathrm{molec} / \mathrm{cm}^{2}$, except at Kiruna (for both instruments) and at Neumayer for GOME-2A. RMS are generally larger for Antarctic stations. 


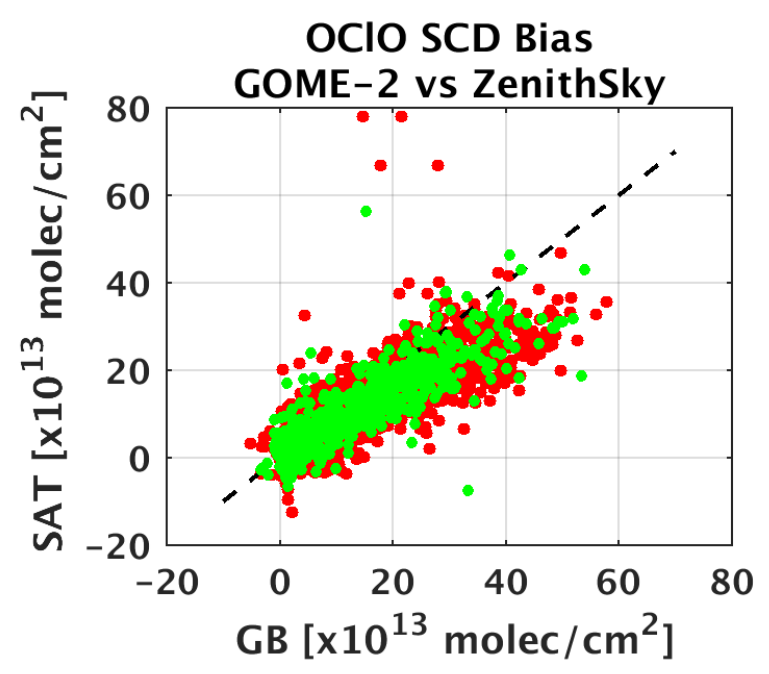

$$
\begin{array}{ll}
\text { GOME-2A }(\# 1361) & \text { GOME-2B }(\# 777) \\
R=0.8, S=0.64 & \mathrm{R}=0.87, \mathrm{~S}=0.72 \\
\text { Offset }=2.1 \mathrm{e}+13 & \text { Offset }=8.7 \mathrm{e}+12 \\
\mathrm{RMS}=7.9 \mathrm{e}+13 & \mathrm{RMS}=6.3 \mathrm{e}+13
\end{array}
$$

Figure 17. Scatter plot between daily GOME-2A (red) and GOME-2B (green) GDP 4.8 satellite data and ground-based data for all the stations included in the study, during active period months.

These results are to be put in perspective with the systematic bias estimated in Sect. 3.1.1 and summarized in Table 3. Some stations have larger expected biases than others (e.g. Eureka up to 15\%) due to their DOAS settings choices, and in general, there is a total uncertainty within the ground-based datasets of about 26 to $33 \%$.

When considering results grouped by hemisphere, the slope is larger in the northern hemisphere for GOME-2A $(0.85$ wrt 0.61), while for GOME-2B results are more coherent (0.76 and 0.7). For GOME-2B the relative bias is very similar in both hemispheres (around -24\%), while for GOME-2A it is about $-5 \%$ in the northern hemisphere and $-30 \%$ in the southern hemisphere.

To summarize, we can conclude that:

- The variability of the OClO column, from day-to-day fluctuations to the annual cycle, is captured consistently by all instruments.

- GOME-2A tends to be noisier than GOME-2B after late 2011. 

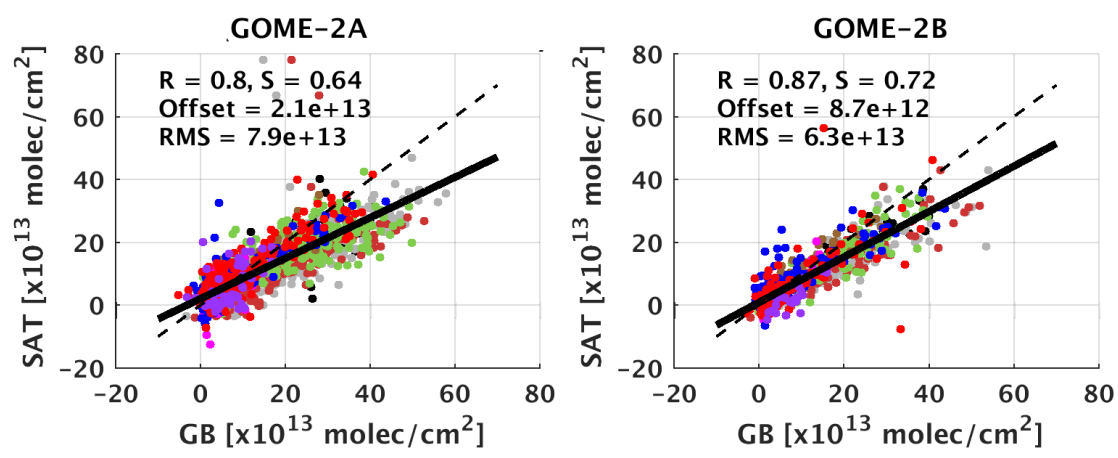

\begin{tabular}{|c|c|}
\hline - & Belgrano \\
\hline - & ArrivalHeights(NIWA) \\
\hline - & ArrivalHeights (IUPH) \\
\hline - & Neumayer \\
\hline - & Marambio \\
\hline - & Harestua \\
\hline - & Kiruna \\
\hline - & NyAlesund \\
\hline - & Eureka \\
\hline
\end{tabular}

Figure 18. Scatter plot between daily GOME-2A (left) and GOME-2B (right) GDP 4.8 satellite data and ground-based data at the different stations included in the study, for the activated months (JAS for stations in the SH and JFM for stations in the NH). The stations are colorcoded, and the total regression statistics are given as insert.

\section{Conclusions}

We investigated the quality of the GOME-2A (2007-2016) and GOME-2B (2012-2016) OClO GDP 4.8 slant column datasets by comparing them to ground-based ZSL-DOAS measurements at a selection of 8 stations located in the Arctic and Antarctic regions: Eureka $\left(80^{\circ} \mathrm{N}\right)$, Ny-Ålesund $\left(79^{\circ} \mathrm{N}\right)$, Kiruna $\left(68^{\circ} \mathrm{N}\right)$, Harestua $\left(60^{\circ} \mathrm{N}\right)$, Marambio $\left(64^{\circ} \mathrm{S}\right)$, Neumayer $\left(71^{\circ} \mathrm{S}\right)$, Belgrano $\left(78^{\circ} \mathrm{S}\right)$ and Arrival Heights $\left(78^{\circ} \mathrm{S}\right)$.

For ground-based instruments, $\mathrm{OClO}$ spectral analyses were performed using fixed noon spectra recorded at low SZA in the absence of chlorine activation. Different DOAS analysis settings are used by different instrument teams, and the impact of these differences are quantified through dedicated sensitivity tests. This leads to an estimation of systematic uncertainties of about 25\% maximum. Depending on the different instruments, the random noise error was estimated to be between 6 and $22 \%$. The total uncertainty from each ground-based dataset is estimated to be between 26 to $33 \%$, depending on the site.

At each station, daily comparisons were performed by selecting satellite and ground-based SCD data pairs corresponding to similar SZA conditions, assuming similar AMFs in both nadir and zenith geometries. Using radiative transfer simulations, this assumption was shown to be valid within the SZA range of the measurements, confirming estimations from previous studies.

Daily mean OClO SCD time-series show that satellite and ground-based observations agree well at all stations, and display consistent seasonal and inter-annual variabilities. GOME-2A tends to be noisier than GOME-2B especially after 2011, which is likely related to instrumental degradation effects combined with the possible impact of the different instrumental corrections applied to the two instruments.

Daily scatterplots based on data selected during chlorine activated periods give correlation coefficients of 0.8 for GOME$2 \mathrm{~A}$ and 0.87 for GOME-2B, and regression slopes are 0.64 for GOME-2A and 0.72 for GOME-2B. These results fulfill the GOME-2 accuracy requirements for OClO, as stated in the EUMETSAT AC SAF Product Requirement Document, i.e. a target accuracy of $50 \%$ and an optimal accuracy of $30 \%$. 

Those biases do not seem to originate from the ground-based datasets since these were also used recently for TROPOMI $\mathrm{OClO}$ validation (Pinardi et al., 2020), showing excellent agreement. Overall, comparison points at all the stations display a median bias of about $-2.2 \times 10^{13} \mathrm{molec} / \mathrm{cm}^{2}$ for both GOME-2 instruments.

We conclude that the AC SAF 2007-2016 GOME-2 GDP 4.8 OClO SCD data records (publicly available through the acsaf.eoc.dlr.de FTP server) meet AC SAF mission requirements for both OClO GOME2 product, but show an under-estimation of about $20-25 \%$ with respect to reference ground-based data.

Room exists for further improvement of both satellite and ground-based data sets. An harmonization of ground-based zenithsky analysis, e.g., by NDACC would be desirable when possible, considering the different spectral ranges covered by the different instruments. Moreover, 3D Chemistry Transport Model output coupled to a suitable radiative transport model could allow creating meaningful OClO AMFs to transform the SCD OClO product into a more directly exploitable VCD product.

\section{Appendix A: Ground-based}

\section{A1 Ground-based sites description}

For this study, stations operating Zenith-Scattered Light (ZSL)-DOAS UV-Visible spectrometers from the Network for the Detection of Atmospheric Composition Change (NDACC, https://www.ndaccdemo.org/, last access on 28 June 2021), situated above $60^{\circ}$ latitude (North and South) and performing OClO SCD data retrievals have been selected.

In the Arctic:

- UToronto operates the PEARL UV-VIS spectrometer at Eureka $\left(80^{\circ} \mathrm{N}, 85.93^{\circ} \mathrm{W}\right.$, Nunavut, northern Canada). OClO SCD data have been analysed since 2011.

- IUP-Bremen operates a UV-VIS spectrometer at Ny-Ålesund $\left(78.9^{\circ} \mathrm{N}, 11.9^{\circ} \mathrm{E}\right.$, Spitsbergen) since 1995 (Wittrock et al., 2004; Tørnkvist et al., 2002). OClO SCDs have been analysed since 2007 using one fixed reference for each season.

- MPIC operates a UV-VIS spectrometer at Kiruna $\left(67.8^{\circ} \mathrm{N}, 20.4^{\circ} \mathrm{E}\right.$, Sweden) since 1996 (Gu, 2019; Bugarski, 2003; Gottschalk, 2013). OClO SCDs have been analysed since 2007, but between 2007 and 2013 the instrument was not operated on many days due to detector problems that prevented the $\mathrm{OClO}$ analysis.

- BIRA-IASB operates a UV-VIS spectrometer at Harestua $\left(60.22^{\circ} \mathrm{N}, 10.75^{\circ} \mathrm{E}\right.$, Norway) since the nineties (Hendrick et al., 2007). End of 2012 a new instrument has been installed with an improved signal to noise ratio, and OClO SCDs have been analysed since then using annual reference spectra.

In the Antarctic:

- IUP-Heidelberg operates a UV-VIS spectrometer at the German Antarctic research station Neumayer $\left(70.62^{\circ} \mathrm{S}, 8.27^{\circ} \mathrm{W}\right.$, on the ice shelf in the Atlantic sector of the Antarctic continent) since the 1999 (Frieß et al., 2004, 2005). OClO SCDs 
https://doi.org/10.5194/amt-2021-356

Preprint. Discussion started: 29 November 2021

(C) Author(s) 2021. CC BY 4.0 License.

\section{Atmospheric Measurement Techniques \\ Discussions}

have been analysed since 2007 using several fixed reference spectra. Generally enhanced OClO signals are observed between August and October, when the polar vortex is over the station.

- IUP-Heidelberg and NIWA jointly operate a UV-VIS spectrometer at Arrival Heights $\left(77.83^{\circ} \mathrm{S}, 166.65^{\circ} \mathrm{W}\right)$, part of the New Zealand station Scott Base on Ross Island since 1998 (Frieß et al., 2005). Another instrument was present at the station, operated by NIWA (Kreher et al., 1996), but stopped measurements in 2017. Both instruments provide OClO SCDs since 2007.

- In 1995, INTA installed a zenith-DOAS Vis at Belgrano II station $\left(77.9^{\circ} \mathrm{S}, 34.6^{\circ} \mathrm{W}\right)$, the Argentinian station situated on the coast of the Antarctic continent in the Weddell Sea area (Yela et al., 2005, 2017). Belgrano is representative of an in-polar vortex station during winter-spring season until the vortex breakdown (Yela et al., 2005, 2017). In 2011, a MAX-DOAS UV/Vis was installed at Belgrano II (Prados-Roman et al., 2018; Gomez-Martin et al., 2021). OCIO SCD have been analysed in the UV channel for 2011, 2014, 2015, 2016, 2018 and 2019. Ground-based SCDs measurements are made for $\mathrm{SZA}<92^{\circ}$, with no measurements during the polar night period (mid-April to mid-August).

- In 1994, INTA installed a zenith-DOAS Vis at Marambio station $\left(64.3^{\circ} \mathrm{S}, 56.7^{\circ} \mathrm{W}\right)$, in Marambio Island (Yela et al., 2017). In 2015, a MAX-DOAS UV/Vis was installed in the same site (Prados-Roman et al., 2018). Marambio is frequently located in the vortex edge region and affected by both vortex air masses and mid-latitude air masses (Aun et al., 2020). OClO SCD have been analysed in the UV channel for 2015 and for 2018 onward.

Table A1. Information on ground-based DOAS instruments.

\begin{tabular}{|c|c|c|c|c|}
\hline Station & Group & Coordinates & $\begin{array}{c}\text { Resolution } \\
\text { [nm] }\end{array}$ & $\begin{array}{c}\text { wvl range } \\
\text { [nm] }\end{array}$ \\
\hline Eureka & UToronto & $80.05^{\circ} \mathrm{N}, 86.42^{\circ} \mathrm{W}$ & 0.5 & $320-400$ \\
\hline Ny-Ålesund & IUPB & $78.9^{\circ} \mathrm{N}, 11.9^{\circ} \mathrm{E}$ & 0.5 & $302-390.8$ \\
\hline Kiruna & MPIC & $67.8^{\circ} \mathrm{N}, 20.4^{\circ} \mathrm{E}$ & 0.6 & $300-400$ \\
\hline Harestua & BIRA & $60.2^{\circ} \mathrm{N}, 10.7^{\circ} \mathrm{E}$ & 0.5 & $290.2-379$ \\
\hline Belgrano & INTA & $77.9^{\circ} \mathrm{S}, 34.6^{\circ} \mathrm{W}$ & 0.5 & $320.5-415.5$ \\
\hline Marambio & INTA & $64.3^{\circ} \mathrm{S}, 56.7^{\circ} \mathrm{W}$ & 0.5 & $327.5-407.5$ \\
\hline Neumayer & IUPH & $70.6^{\circ} \mathrm{S}, 8.3^{\circ} \mathrm{W}$ & 0.5 & $320-420$ \\
\hline Arrival Heights & IUPH & $77.8^{\circ} \mathrm{S}, 166.6^{\circ} \mathrm{W}$ & 0.5 & $320-420$ \\
\hline Arrival Heights & NIWA & $77.8^{\circ} \mathrm{S}, 166.6^{\circ} \mathrm{W}$ & 0.56 & $402-440$ \\
\hline
\end{tabular}

\section{A2 Sensitivity tests}

Systematic errors: 
In a first test, OCIO SCD analysis are performed in the 345-389nm range (as for the GOME-2 analysis window, with varying OClO cross-section sources (using the Wahner et al. (1987), the Kromminga et al. (1999) and the Kromminga et al. (2003) cross-sections at several temperatures), and fixing the other inputs, as summarized in Table A2. With respect to Kromminga et al. (2003) at 213K (used for GOME-2 analysis), regression analysis reveals slopes of 1.02 for the Kromminga et al. (2003) at $233 \mathrm{~K}, 0.97$ for the Kromminga et al. (1999) also at 213K and of 0.85 for the Wahner et al. (1987) at 204K (see Fig. A1), so a total uncertainty of about $15 \%$ with respect to what used for GOME-2 retrievals. This is coherent with Kromminga et al. (2003) reporting cross-section band peaks about 8\% smaller than Wahner et al. (1987).

Considering the largest impact between results obtained with the different OClO cross-sections, we come to a difference of about $17 \%$ (corresponding to slopes ranging from 0.85 to 1.02). This value is used to quantify the first component of the systematic uncertainty in Table A2. The expected bias for each group OClO cross-section choice is also reported for each station in Table 3.

435 For the second test (see Table A2), we fixed the OClO cross-section to Kromminga et al. (2003) at 213K and varied the other DOAS fit parameters in an attempt to match the different settings used by each group (wavelength interval, interfering species and their cross-section references as in Table 2). Unfortunately, the Ny-Ålesund instrument does not cover the visible range and stops at $390.4 \mathrm{~nm}$ and the MPIC wavelength choice (interval 372-392nm) cannot be entirely covered. It should be noted that no analysis could be done in the visible interval used by NIWA.

Results of the regression analysis for each group choice with respect to the median OCIO SCD values, are presented in Figure A2. In most cases, the regression is compact (correlation $\mathrm{R}$ larger than 0.945) except for MPIC ( $\mathrm{R}=0.893$ ), also the RMS is generally smaller than $2 \times 10^{13} \mathrm{molec} / \mathrm{cm}^{2}$, except for IUPH and MPIC. Results for the latter two cases are likely biased due to the limited wavelength range (up to about $390.4 \mathrm{~nm}$ ) of the Ny-lesund spectra. As a result in these cases, the upper part of the wavelength interval is not covered. Depending on the setting choices, the difference compared to the median OClO SCD can take the form of a multiplicative bias (slope different than 1) and/or an additive bias (non-zero intercept). In the tested cases, all intercept except for IUPH are smaller than $1 \times 10^{13} \mathrm{molec} / \mathrm{cm}^{2}$, so the observed bias is mostly multiplicative. The largest impact on the slope is obtained for the MPIC case (slope of 0.925) and for UToronto (1.04), leading to a difference between all cases of about $18.5 \%$ (slopes from 0.925 to 1.11). This value is considered as the maximum systematic uncertainty on the retrieval choice for the systematic uncertainty contribution in Table A2, leading to a total maximum systematic uncertainty of about $25 \%$ (see Table A2).

\section{Expected systematic bias against GOME-2:}

A third test has been carried out (see Table A2), comparing each group analysis to the OClO SCD obtained using the GOME2 data retrieval settings (345-389nm range, see Table 1), as illustrated in Fig. A3. From this sensitivity test, the expected systematic bias for each group is estimated in comparison to the GOME-2 retrieval settings, ranging between $4 \%$ and $16 \%$ for the different stations. 
Table A2. Description of the different sensitivity tests performed and main results summary. The letters refer to Table 2.

\begin{tabular}{|c|c|c|c|c|c|c|c|c|c|}
\hline \multirow[t]{2}{*}{ Tests } & \multirow{2}{*}{$\begin{array}{l}\text { wavelength } \\
\text { range }(\mathrm{nm})\end{array}$} & \multicolumn{6}{|c|}{ Cross-sections } & slopes & \multirow{2}{*}{$\begin{array}{l}\text { Syst. } \\
\text { Contr. }\end{array}$} \\
\hline & & $\mathrm{OClO}$ & $\mathrm{NO}_{2}$ & $\mathrm{O}_{3}$ & $\mathrm{BrO}$ & $\mathrm{O}_{4}$ & Ring & $\min , \max$ & \\
\hline 1) $\mathrm{OClO}$ cross & $345-389$ & ${ }^{a}(204 \mathrm{~K}),{ }^{b}(213 \mathrm{~K})$ & $(220 \mathrm{~K})^{*}$ & $23 \mathrm{~K}, 243 \mathrm{~K})^{*}$ & $-t$ & ${ }^{l}(298 \mathrm{~K})$ & Ring & $0.85,1.02$ & $17 \%$ \\
\hline sections & & ${ }^{c}(213 \mathrm{~K}, 233 \mathrm{~K})$ & Gur2005 & Gur2005 & & & Vountas & & \\
\hline \multirow{3}{*}{$\begin{array}{l}\text { 2) retrieval choices } \\
\text { vs median }\end{array}$} & as Table 2 & ${ }^{c}(213 \mathrm{~K})$ & & as Tab & ole 2 & & & $0.925,1.11$ & $18.5 \%$ \\
\hline & & & & & & & & & \\
\hline & & & & & & & & & $25 \%$ \\
\hline 3) retrieval choices & as Table 2 & ${ }^{c}(213 \mathrm{~K})$ & & as Tab & ole 2 & & & $0.84,1.03$ & $19 \%$ \\
\hline vs GOME-2 (Table1) & & & & & & & & & \\
\hline
\end{tabular}
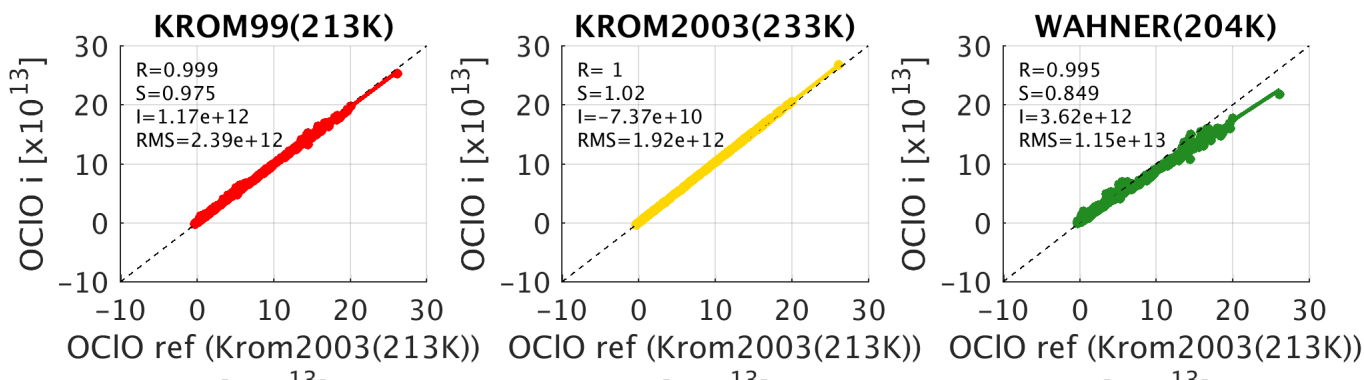

$$
\left[\times 10^{13}\right]
$$

$\left[\times 10^{13}\right]$

$\left[\times 10^{13}\right]$

Figure A1. Regression analysis of OClO SCD retrieved from a common set of Ny-lesund spectra to investigate the sensitivity of OClO results on cross-sections used. The different DOAS analysis used correspond to what described in Table A2, for tests 1), with respect to OClO values obtained using the Kromminga et al (2003) cross-section at $213 \mathrm{~K}$ as in GOME-2.

Author contributions. GP carried out the validation analysis, the associated investigations and wrote the manuscript. MVR and FH contributed input and advise at all stages of the scientific discussions and of the manuscript writing. MVR prepared the ground-based offset correction, FH performed the AMF calculations and JG pre-processed the satellite data. AR and PV developed the GOME-2 OClO data processor. MVR, FH, AR, FW, UF, RQ, PJ, KB, KS, MG, TW, MYG, CPR analysed the ground-based data and/or supervised the instrument operation. All co-authors revised and commented on the manuscript.

Competing interests. The authors declare that they have no conflict of interest. 

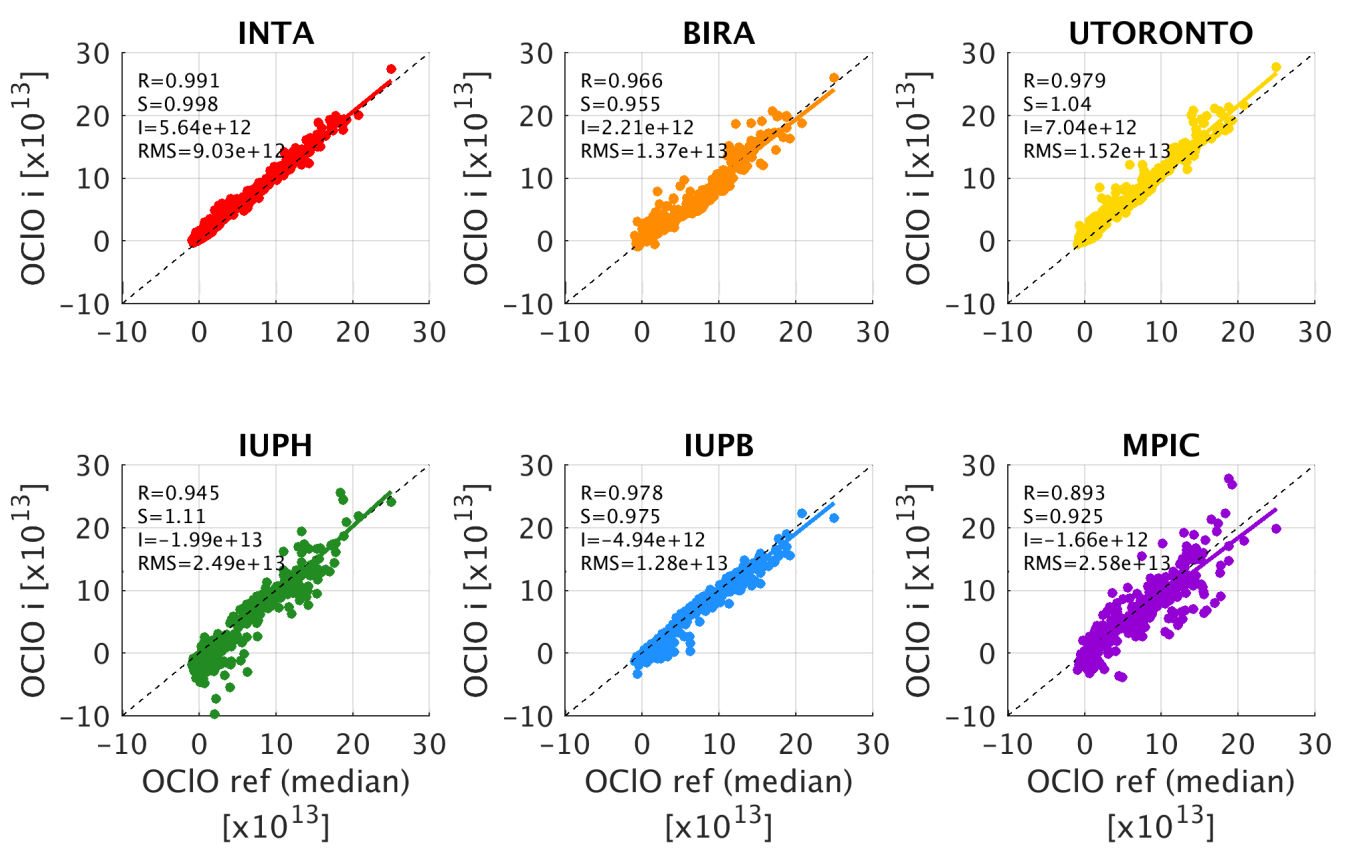

Figure A2. Regression analysis of OClO SCD retrieved from a common set of Ny-lesund spectra to investigate the sensitivity of OClO results on different settings. The different DOAS analyses used correspond to those used by each group for their own station analysis, as described in Table 2 and A2 in tests 2). Each set of OClO SCD is compared against median OClO values and regression statistics are given as inset in each plot.

Acknowledgements. Part of the reported work was carried out in the framework of the EUMETSAT AC SAF Continuous Development and Operations Phase (CDOP-2 and -3), and by the Belgian Federal Science Policy Office (BELSPO) via the ProDEx BeACSAF contribution to the AC-SAF. EUMETSAT and the AC SAF are acknowledged for the production of GOME-2 GDP 4.8 data.

The authors are also grateful to O. Rasson for valuable IT support and for their dedication to the AC SAF operational validation.

The ZSL-DOAS data used in this publication were obtained from the PIs, and stations are part of the Network for the Detection of Atmospheric Composition Change (NDACC, https://ndacc.org). The ZSL-DOAS instrument PIs and staff at the stations are warmly thanked for their sustained effort on maintaining high quality measurements and for valuable scientific discussions. MPIC whish to thank Carl-Fredrik Enell and Uwe Raffalksi for operating the Kiruna DOAS instrument. The ZSL-DOAS measurements at Eureka were made at the Polar Environment Atmospheric Research Laboratory (PEARL) by the Canadian Network for the Detection of Atmospheric Change (CANDAC), primarily supported by the Canadian Space Agency, the Natural Sciences and Engineering Research Council, and Environment and Climate Change Canada. INTA's observations were funded by the Spanish Ministry of Science and Innovation under the projects VHODCA (CTM2017-83199P), HELADO (CTM2013-41311P) and VIOLIN (CGL2010-20353). NIWA measurements at Arrival Heights are supported through New Zealand's Ministry of Business, Innovation and Employment (MBIE) Strategic Science Investment Fund (SSIF). 

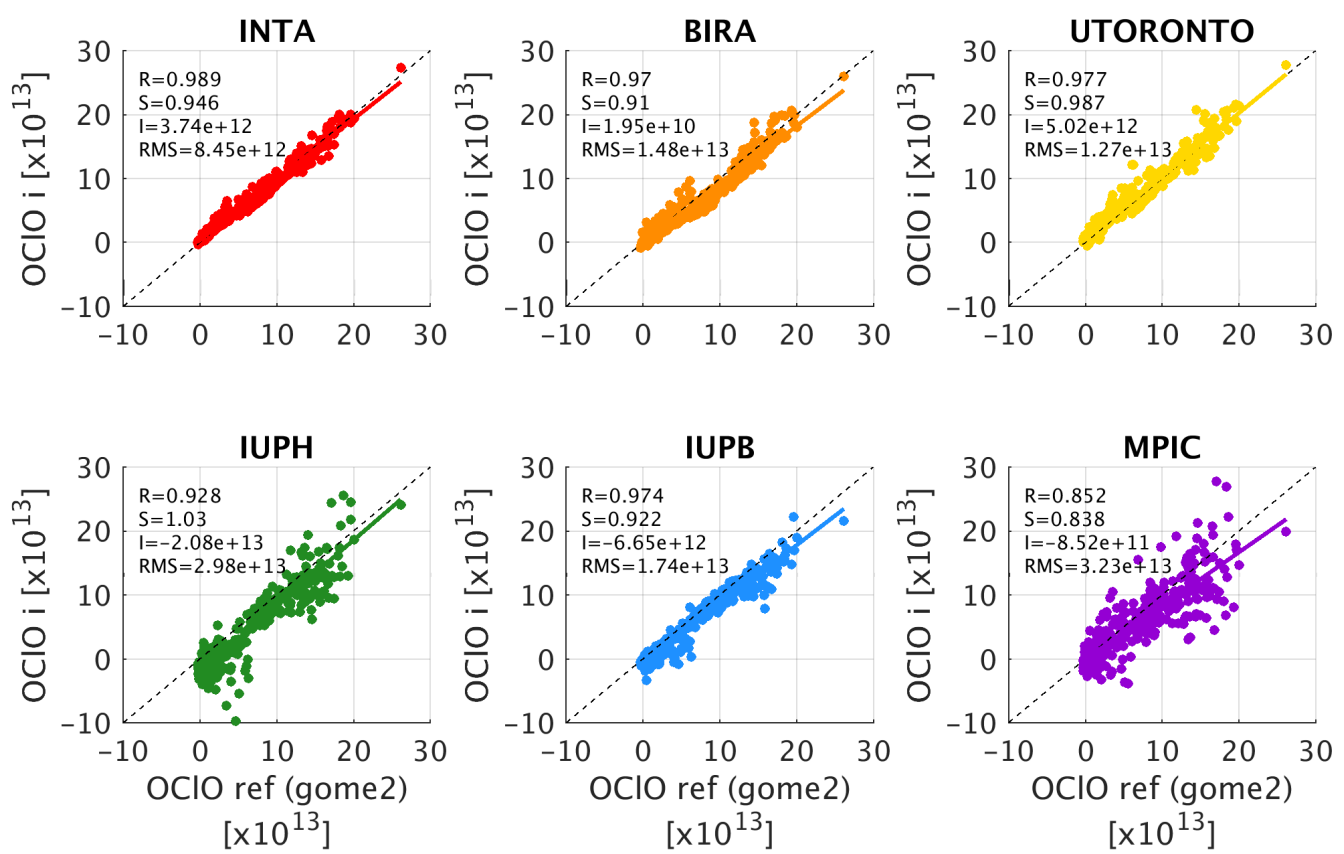

Figure A3. Regression analysis of OClO SCD retrieved from a common set of Ny-lesund spectra to investigate the sensitivity of OClO results on different settings. The different DOAS analysis used correspond to what each group used for their own station analysis, as described in Table 2 and A2 in test 3). Each set of OClO SCD is compared against the OClO values obtained using the GOME-2 retrieval settings described in Table 1 and regression statistics are given as inset for each plot.

\section{References}

Aliwell, S. R., Van Roozendael, M., Johnston, P. V., Richter, A., Wagner, T., Arlander, D. W., Burrows, J. P., Fish, D. J., Jones, R. L., Tørnkvist, K. K., Lambert, J.-C., Pfeilsticker, K., and Pundt, I.: Analysis for BrO in zenith-sky spectra: An intercomparison exercise for analysis improvement, Journal of Geophysical Research: Atmospheres, 107, ACH 10-1-ACH 10-20, https://doi.org/https://doi.org/10.1029/2001JD000329, 2002.

Aun, M., Lakkala, K., Sanchez, R., Asmi, E., Nollas, F., Meinander, O., Sogacheva, L., De Bock, V., Arola, A., de Leeuw, G., Aaltonen, V., Bolsée, D., Cizkova, K., Mangold, A., Metelka, L., Jakobson, E., Svendby, T., Gillotay, D., and Van Opstal, B.: Solar UV radiation measurements in Marambio, Antarctica, during years 2017-2019, Atmospheric Chemistry and Physics, 20, 6037-6054, https://doi.org/10.5194/acp-20-6037-2020, 2020.

Bogumil, K., Orphal, J., Homann, T., Voigt, S., Spietz, P., Fleischmann, O., Vogel, A., Hartmann, M., Bovensmann, H., Frerik, J., and Burrows, J. P.: Measurements of molecular absorption spectra with the SCIAMACHY pre-flight model: instrument characterization and reference data for atmospheric remote-sensing in the 230-2380 nm region, Journal of Photochemistry and Photobiology A: Chemistry, 157, 167-184, https://doi.org/10.1016/S1010-6030(03)00062-5, 2003. 
https://doi.org/10.5194/amt-2021-356

Preprint. Discussion started: 29 November 2021

(C) Author(s) 2021. CC BY 4.0 License.
Atmospheric

Measurement

Techniques

Discussions

Brion, J., Chakir, A., Charbonnier, J., Daumont, D., Parisse, C., , and Malicet, J.: Absorption spectra measurements for the ozone molecule in the 350-830 nm region, Journal of Atmospheric Chemistry, 30, 291-299, https://doi.org/10.1023/A:1006036924364, 1998.

Bugarski, S.: Spektroskopische Messungen der stratosphärischen Spurengase BrO und OClO in Kiruna (Schweden), Diploma thesis, institute for applied physics of the technical, university of darmstadt, 2003.

Burrows, J. P., Weber, M., Buchwitz, M., Rozanov, V., A., L.-W., A., R., DeBeek, R., Hoogen, R., Bramstedt, K., Eichmann, K. U., Eisinger, M., and Perner, D.: The Global Ozone Monitoring Experiment (GOME): Mission Concept and First Scientific Results, J. Atmos. Sci., 56, $151-175,1999$.

Chance, K. and Kurucz, R.: An improved high-resolution solar reference spectrum for earth's atmosphere measurements in the ultraviolet, visible, and near infrared, Journal of Quantitative Spectroscopy and Radiative Transfer, 111, 1289-1295, https://doi.org/https://doi.org/10.1016/j.jqsrt.2010.01.036, 2010.

Chance, K. V. and Spurr, R. J. D.: Ring effect studies: Rayleigh scattering, including molecular parameters for rotational Raman scattering, and the Fraunhofer spectrum, Appl. Opt., 36, 5224-5230, https://doi.org/10.1364/AO.36.005224, 1997.

Fleischmann, O. C., Hartmann, M., Burrows, J. P., and Orphal, J.: New ultraviolet absorption cross-sections of BrO at atmospheric temperatures measured by time-windowing Fourier transform spectroscopy, Journal of Photochemistry and Photobiology A: Chemistry, 168, 117 - 132, https://doi.org/https://doi.org/10.1016/j.jphotochem.2004.03.026, 2004.

Frieß, U., Hollwedel, J., König-Langlo, G., Wagner, T., and Platt, U.: Dynamics and chemistry of tropospheric bromine explosion events in the Antarctic coastal region, Journal of Geophysical Research: Atmospheres, 109, https://doi.org/https://doi.org/10.1029/2003JD004133, 2004.

Frieß, U., Kreher, K., Johnston, P. V., and Platt, U.: Ground-Based DOAS Measurements of Stratospheric Trace Gases at Two Antarctic Stations during the 2002 Ozone Hole Period, Journal of the Atmospheric Sciences, 62, 765-777, https://doi.org/10.1175/JAS-3319.1, 2005.

510 Gil, M., Puentedura, O., Yela, M., Parrondo, C., Jadhav, D. B., and Thorkelsson, B.: OClO, $\mathrm{NO}_{2}$ and $\mathrm{O}_{3}$ total column observations over Iceland during the winter 1993/94, Geophys. Res. Lett., 23, 3337-3340, https://doi.org/10.1029/96GL03102, 1996.

Gomez-Martin, L., Toledo, D., Prados-Roman, C., Adame, J. A., Ochoa, H., and Yela, M.: Polar Stratospheric Clouds Detection at Belgrano II Antarctic Station with Visible Ground-Based Spectroscopic Measurements, Remote Sensing, 13, https://doi.org/10.3390/rs13081412, 2021.

515 Gottschalk, M.: Characterisation of a new CCD-Detector for the Zenith-DOAS in Kiruna,Sweden, Bachelor thesis, johannes gutenberguniversity of mainz, 2013.

Greenblatt, G. D., Orlando, J. J., Burkholder, J. B., and Ravishankara, A. R.: Absorption measurements of oxygen between 330 and 1140 nm, Journal of Geophysical Research: Atmospheres, 95, 18 577-18 582, https://doi.org/https://doi.org/10.1029/JD095iD11p18577, 1990.

$\mathrm{Gu}$, M.: Long term trends of Stratospheric trace gases from ground-based DOAS observations of Kiruna, Sweden, Phd thesis, university of heidelberg, http://www.ub.uni-heidelberg.de/archiv/25980, 2019.

Gür, B., Spietz, P., Orphal, J., and Burrows, J.: Absorption Spectra Measurements with the GOME-2 FMs using the IUP/IFE-UB's Calibration Apparatus for Trace Gas Absorption Spectroscopy CATGAS, Final Report, Tech. rep., IUP University of Bremen, 2005.

Hassinen, S., Balis, D., Bauer, H., Begoin, M., Delcloo, A., Eleftheratos, K., Gimeno Garcia, S., Granville, J., Grossi, M., Hao, N., Hedelt, P., Hendrick, F., Hess, M., Heue, K.-P., Hovila, J., Jønch-Sørensen, H., Kalakoski, N., Kauppi, A., Kiemle, S., Kins, L., Koukouli, M. E., Kujanpää, J., Lambert, J.-C., Lang, R., Lerot, C., Loyola, D., Pedergnana, M., Pinardi, G., Romahn, F., van Roozendael, M., Lutz, R., De Smedt, I., Stammes, P., Steinbrecht, W., Tamminen, J., Theys, N., Tilstra, L. G., Tuinder, O. N. E., Valks, P., Zerefos, C., Zimmer, W., 
https://doi.org/10.5194/amt-2021-356

Preprint. Discussion started: 29 November 2021

(C) Author(s) 2021. CC BY 4.0 License.
Atmospheric

Measurement

Techniques

Discussions

and Zyrichidou, I.: Overview of the O3M SAF GOME-2 operational atmospheric composition and UV radiation data products and data availability, Atmospheric Measurement Techniques, 9, 383-407, https://doi.org/10.5194/amt-9-383-2016, 2016.

Hendrick, F., Van Roozendael, M., Chipperfield, M. P., Dorf, M., Goutail, F., Yang, X., Fayt, C., Hermans, C., Pfeilsticker, K., Pommereau,

J.-P., Pyle, J. A., Theys, N., and De Mazière, M.: Retrieval of stratospheric and tropospheric BrO profiles and columns using ground-based zenith-sky DOAS observations at Harestua, 60deg; N, Atmospheric Chemistry and Physics, 7, 4869-4885, https://doi.org/10.5194/acp-74869-2007, 2007.

Hermans, C., Vandaele, A. C., Carleer, M., Fally, S., Colin, R., Jenouvrier, A., Coquart, B., and Mérienne, M.-F.: Absorption cross-sections of atmospheric constituents: NO2, O2, and H2O, Environmental Science and Pollution Research, 6, 151-158, 1999.

Hermans, C., Vandaele, A. C., Fally, S., Carleer, M., Colin, R., Coquart, B., Jenouvrier, A., and Merienne, M.-F.: Fourier transform measurements of SO2 absorption cross sections:: I. Temperature dependence in the 24000-29000cm-1 (345-420nm) region, Proceedings of the NATO Advanced Research Workshop, Weakly Interacting Molecular Pairs: Unconventional Absorbers of Radiation in the Atmospher, NATO Science Series IV Earth and Environmental Sciences e, 27, 193-202, http://spectrolab.aeronomie.be/o2.htm, 2003.

Kreher, K., Keys, J. G., Johnston, P. V., Platt, U., and Liu, X.: Ground-based measurements of OClO and HCl in austral spring 1993 at Arrival Heights, Antarctica, Geophysical Research Letters, 23, 1545-1548, https://doi.org/https://doi.org/10.1029/96GL01318, 1996.

Kromminga, H., Voigt, S., Orphal, J., and Burrows, J.: UV-Visible FT Spectra of OClO at Atmospheric Temperatures, Tech. rep., Proceedings of the 1stEuropean Symposium on Atmospheric Measurements from Space, ESA Special Publication, 1999.

Kromminga, H., Orphal, J., Spietz, P., Voigt, S., and Burrows, J.: New measurements of OClO absorption cross-sections in the 325-435 nm region and their temperature dependence between 213 and 293 K, Journal of Photochemistry and Photobiology A: Chemistry, 157, 149 160, https://doi.org/https://doi.org/10.1016/S1010-6030(03)00071-6, atmospheric Photochemistry, 2003.

Kuttippurath, J., S.Godin-Beekmann, Lefèvre, F., and Pazmiño, A.: Ozone depletion in the Arctic winter 2007-2008, International Journal of Remote Sensing, 30, 4071-4082, https://doi.org/10.1080/01431160902821965, 2009.

Kühl, S., Wilms-Grabe, W., Beirle, S., Frankenberg, C., Grzegorski, M., Hollwedel, J., Khokhar, F., Kraus, S., Platt, U., Sanghavi, S., von Friedeburg, C., and Wagner, T.: Stratospheric chlorine activation in the Arctic winters 1995/96-2001/02 derived from GOME OClO measurements, Advances in Space Research, 34, 798 - 803, https://doi.org/https://doi.org/10.1016/j.asr.2003.08.069, trace Constituents in the Troposphere and Lower Stratosphere, 2004.

Kühl, S., Wilms-Grabe, W., Frankenberg, C., Grzegorski, M., Platt, U., and Wagner, T.: Comparison of OClO nadir measurements from SCIAMACHY and GOME, Advances in Space Research, 37, 2247 - 2253, https://doi.org/https://doi.org/10.1016/j.asr.2005.06.061, atmospheric Remote Sensing: Earth's Surface, Troposphere, Stratosphere and Mesosphere - II, 2006.

McElroy, M. B., Salawitch, R. J., Wofsy, S. C., and Logan, J. A.: Reductions of Antarctic ozone due to synergistic interactions of chlorine and bromine, Nature, 321, 759-762, https://doi.org/10.1038/321759a0, 1986.

Meier, A., Richter, A., Pinardi, G., and Lerot, C.: Monitoring Stratospheric OClO with Sentinel-5p (S5pOClO), Algorithm Theoretical Baseline Document, Tech. rep., S5p+I_OCLO_IUP-UB_ATBD v2, http://www.doas-bremen.de/projects/s5p_oclo/S5p+I_OClO_IUP-UB_ ATBD_V2-2_final.pdf, 2020.

Molina, L. T. and Molina, M. J.: Production of chlorine oxide (Cl2O2) from the self-reaction of the chlorine oxide (ClO) radical, The Journal of Physical Chemistry, 91, 433-436, https://doi.org/10.1021/j100286a035, 1987.

Munro, R., Lang, R., Klaes, D., Poli, G., Retscher, C., Lindstrot, R., Huckle, R., Lacan, A., Grzegorski, M., Holdak, A., Kokhanovsky, A., Livschitz, J., and Eisinger, M.: The GOME-2 instrument on the Metop series of satellites: instrument design, calibration, and level 1 data 
https://doi.org/10.5194/amt-2021-356

Preprint. Discussion started: 29 November 2021

(C) Author(s) 2021. CC BY 4.0 License.
Atmospheric

Measurement

Techniques

Discussions

processing

- an overview, Atmospheric Measurement Techniques, 9, 1279-1301, https://doi.org/10.5194/amt-9-1279-2016, 2016.

Oetjen, H., Wittrock, F., Richter, A., Chipperfield, M. P., Medeke, T., Sheode, N., Sinnhuber, B.-M., Sinnhuber, M., and Burrows, J. P.: Evaluation of stratospheric chlorine chemistry for the Arctic spring 2005 using modelled and measured OClO column densities, Atmospheric Chemistry and Physics, 11, 689-703, https://doi.org/10.5194/acp-11-689-2011, 2011.

OMOCLOv3: Harvard-Smithsonian Center for Astrophysics, OMOCLO v3.0, https://www.cfa.harvard.edu/atmosphere/Instruments/OMI/ PGEReleases/.

Otten, C., Ferlemann, F., Platt, U., Wagner, T., and Pfeilsticker, K.: Groundbased DOAS UV/visible measurements at Kiruna (Sweden) during the SESAME winters 1993/94 and 1994/95, J. of Atm. Chem., 30, 141-162, 1998.

Pinardi, G., Richter, A., Meier, A., and Roozendael, M. V.: Monitoring Stratospheric OClO with Sentinel-5p (S5pOClO), Validation Report, Tech.rep., S5p+I_OCLO_BIRA_VR, http://www.doas-bremen.de/projects/s5p_oclo/S5p+I_OClO_BIRA_VR_20201207_v1.1.pdf, 5752020.

Platt, U. and Stutz, J.: Differential Optical Absorption Spectroscopy, Springer, Berlin Heidelberg, https://doi.org/10.1017/CBO9781107415324.004, 2008.

Pommereau, J.-P. and Piquard, J.: Ozone and nitrogen dioxide vertical distributions by UV-visible solar occultation from balloons, Geophysical Research Letters, 21, 1227-1230, https://doi.org/https://doi.org/10.1029/94GL00389, 1994.

Prados-Roman, C., Gómez-Martín, L., Puentedura, O., Navarro-Comas, M., Iglesias, J., de Mingo, J. R., Pérez, M., Ochoa, H., Barlasina, M. E., Carbajal, G., and Yela, M.: Reactive bromine in the low troposphere of Antarctica: estimations at two research sites, Atmospheric Chemistry and Physics, 18, 8549-8570, https://doi.org/10.5194/acp-18-8549-2018, 2018.

Pukīte, J., Kühl, S., Deutschmann, T., Platt, U., and Wagner, T.: Extending differential optical absorption spectroscopy for limb measurements in the UV, Atmospheric Measurement Techniques, 3, 631-653, https://doi.org/10.5194/amt-3-631-2010, 2010.

Pukīte, J., Borger, C., Dörner, S., Gu, M., Frieß, U., Maier, A. C., Enell, C.-F., Raffalksi, U., Richter, A., and Wagner, T.: Retrieval algorithm for OClO from TROPOMI by Differential Optical Absorption Spectroscopy, Atmospheric Measurement Techniques Discussions, 2021, 1-44, https://doi.org/10.5194/amt-2021-178, 2021a.

Pukīite, J., Borger, C., Dörner, S., Gu, M., and Wagner, T.: OClO as observed by TROPOMI: a comparison with meteorological parameters and PSC observations, Atmospheric Chemistry and Physics Discussions, 2021, 1-33, https://doi.org/10.5194/acp-2021-600, 2021b.

Renard, J. B., Lefevre, F., Pirre, M., Robert, C., , and Huguenin, D.: Verticle profile of night-time stratospheric OClO, Journal of Atmospheric Chemistry, 26, 65-76, https://doi.org/10.1023/A:1005757321761, 1997.

Richter, A., Eisinger, M., Ladstätter-Weißenmayer, A., and Burrows, J.: DOAS Zenith Sky Observations: 2. Seasonal Variation of BrO Over Bremen $\left(53^{\circ} \mathrm{N}\right)$ 1994-1995, Journal of Atmospheric Chemistry, 32, 83-99, https://doi.org/10.1023/A:1006077725894, 1999.

Richter, A., Wittrock, F., Weber, M., Beirle, S., Kühl, S., Platt, U., Wagner, T., Wilms-Grabe, W., and Burrows, J. P.: GOME Observations of Stratospheric Trace Gas Distributions during the Splitting Vortex Event in the Antarctic Winter of 2002. Part I: Measurements, Journal of the Atmospheric Sciences, 62, 778 - 785, https://doi.org/10.1175/JAS-3325.1, 2005.

Richter, A., Slijkhuis, S., and Loyola, D.: Offline Total OClO validation report, O3M-11, Tech. rep., SAF/O3M/IUP/OClO/2, http://www. iup.uni-bremen.de/doas/reports/o3saf_vs_gome-2_oclo_finalreport_091208.pdf, 2009.

Richter, A., Wittrock, F., and Valks, P.: Evaluation of the possibility to derive reliable OClO slant columns from GOME-2B and GOME2A spectra, O3M SAF Visiting Scientist Activity, ID 03_AS14_02, Final Report, Tech. rep., SAF/O3M/IUP/OClO/2, http://www.iup. uni-bremen.de/doas/reports/o3m-saf_oclo_2_report_160427.pdf, 2015. 
https://doi.org/10.5194/amt-2021-356

Preprint. Discussion started: 29 November 2021

(C) Author(s) 2021. CC BY 4.0 License.
Atmospheric

Measurement

Techniques

Discussions

Schiller, C., Wahner, A., Platt, U., Dorn, H.-P., Callies, J., and Ehhalt, D. H.: Near UV atmospheric absorption measurements of column abundances during Airborne Arctic Stratospheric Expedition, January - February 1989: 2. OClO observations, Geophysical Research Letters, 17, 501-504, https://doi.org/https://doi.org/10.1029/GL017i004p00501, 1990.

Serdyuchenko, A., Gorshelev, V., Weber, M., Chehade, W., and Burrows, J. P.: High spectral resolution ozone absorption cross-sections ndash; Part 2: Temperature dependence, Atmospheric Measurement Techniques, 7, 625-636, https://doi.org/10.5194/amt-7-625-2014, 2014.

Sessler, J., Chipperfield, M. P., Pyle, J. A., and Toumi, R.: Stratospheric OClO measurements as a poor quantitative indicator of chlorine activation, Geophysical Research Letters, 22, 687-690, https://doi.org/https://doi.org/10.1029/95GL00202, 1995.

Solomon, S.: Stratospheric ozone depletion: A review of concepts and history, Reviews of Geophysics, 37, 275-316, https://doi.org/https://doi.org/10.1029/1999RG900008, 1999.

Solomon, S., Mount, G. H., Sanders, R. W., and Schmeltekopf, A. L.: Visible spectroscopy at McMurdo Station, Antarctica: 2. Observations of OClO, Journal of Geophysical Research: Atmospheres, 92, 8329-8338, https://doi.org/https://doi.org/10.1029/JD092iD07p08329, 1987.

Solomon, S., Mount, G. H., Sanders, R. W., Jakoubek, R. O., and Schmeltekopf, A. L.: Observations of the Nighttime Abundance of OClO in the Winter Stratosphere Above Thule, Greenland, Science, 242, 550-555, https://doi.org/10.1126/science.242.4878.550, 1988.

Solomon, S., Sanders, R. W., and Miller Jr., H. L.: Visible and near-ultraviolet spectroscopy at McMurdo Station, Antarctica 7. OClO diurnal photochemistry and implications for ozone destruction, Journal of Geophysical Research: Atmospheres, 95, 13 807-13817, https://doi.org/https://doi.org/10.1029/JD095iD09p13807, 1990.

Tétard, C., Fussen, D., Bingen, C., Capouillez, N., Dekemper, E., Loodts, N., Mateshvili, N., Vanhellemont, F., Kyrölä, E., Tamminen, J., Sofieva, V., Hauchecorne, A., Dalaudier, F., Bertaux, J.-L., Fanton d'Andon, O., Barrot, G., Guirlet, M., Fehr, T., and Saavedra, L.: Simultaneous measurements of $\mathrm{OClO}, \mathrm{NO}_{2}$ and $\mathrm{O}_{3}$ in the Arctic polar vortex by the GOMOS instrument, Atmospheric Chemistry and Physics, 9, 7857-7866, https://doi.org/10.5194/acp-9-7857-2009, 2009.

Thalman, R. and Volkamer, R.: Temperature dependent absorption cross-sections of O2-O2 collision pairs between 340 and $630 \mathrm{~nm}$ and at atmospherically relevant pressure, Phys. Chem. Chem. Phys., 15, 15 371-15 381, https://doi.org/10.1039/C3CP50968K, 2013.

Toumi, R.: Reaction of $\mathrm{ClO}$ with NO3: OClO formation and night-time O3 loss, Geophysical Research Letters, 21, 1487-1490, https://doi.org/https://doi.org/10.1029/93GL01675, 1994.

Tørnkvist, K. K., Arlander, D. W., and Sinnhuber, B.-M.: Ground-Based UV Measurements of BrO and OClO over Ny-Ålesund during Winter 1996 and 1997 and Andøya during Winter 1998/99, Journal of Atmospheric Chemistry, 43, 75-106, https://doi.org/10.1023/A: $1019905006390,2002$.

Valks, P., Chan, L., Hedelt, P., Slijkhuis, S., and Lutz, R.: Algorithm Theoretical Basis Document for GOME-2 Total Column Products of Ozone, NO2, BrO, HCHO, SO2, H2O, OClO and Cloud Properties (GDP 4.8 for GOME-2 on MetOp-A and -B, GDP 4.9 for GOME-2 on MetOp-C), Tech.rep., DLR/GOME-2/ATBD/01, https://acsaf.org/docs/atbd/Algorithm_Theoretical_Basis_Document_NTO_OTO_Nov_ 2019.pdf, 2019a.

Valks, P., Chan, L., Hedelt, P., Slijkhuis, S., and Lutz, R.: Product User Manual for GOME-2 Total Column Products of Ozone, NO2, BrO, $\mathrm{HCHO}, \mathrm{SO} 2, \mathrm{H} 2 \mathrm{O}, \mathrm{OClO}$ and Cloud Properties (GDP 4.8 for GOME-2 on MetOp-A and -B, GDP 4.9 for GOME-2 on MetOp-C), Tech. rep., DLR/GOME-2/PUM/01, https://acsaf.org/docs/pum/Product_User_Manual_NTO_OTO_Nov_2019.pdf, 2019b. 
https://doi.org/10.5194/amt-2021-356

Preprint. Discussion started: 29 November 2021

(C) Author(s) 2021. CC BY 4.0 License.
Atmospheric

Measurement

Techniques

Discussions

Vandaele, A. C., Hermans, C., Simon, P. C., Carleer, M., Colin, R., Fally, S., Mérienne, M. F., Jenouvrier, A., and Coquart, B.: Measurements of the NO2 absorption cross-section from $42000 \mathrm{~cm}-1$ to $10000 \mathrm{~cm}-1(238-1000 \mathrm{~nm})$ at $220 \mathrm{~K}$ and $294 \mathrm{~K}$, J. Quant. Spectrosc. Radiat. Transf., 59, 171-184, https://doi.org/10.1016/S0022-4073(97)00168-4, 1998.

Vandaele, A. C., Fayt, C., Hendrick, F., Hermans, C., Humbled, F., Van Roozendael, M., Gil, M., Navarro, M., Puentedura, O., Yela, M., Braathen, G., Stebel, K., Tørnkvist, K., Johnston, P., Kreher, K., Goutail, F., Mieville, A., Pommereau, J.-P., Khaikine, S., Richter, A., Oetjen, H., Wittrock, F., Bugarski, S., Frieß, U., Pfeilsticker, K., Sinreich, R., Wagner, T., Corlett, G., and Leigh, R.: An intercomparison campaign of ground-based UV-visible measurements of $\mathrm{NO} 2, \mathrm{BrO}$, and $\mathrm{OClO}$ slant columns: Methods of analysis and results for $\mathrm{NO}_{2}$, $\mathrm{J}_{\text {. }}$ Geophys. Res. Atmos., 110, https://doi.org/10.1029/2004JD005423, 2005.

Vountas, M., Rozanov, V. V., and Burrows, J. P.: Ring effect: impact of rotational Raman scattering on radiative transfer in Earth's atmosphere., , 60, 943-961, https://doi.org/10.1016/S0022-4073(97)00186-6, 1998.

Wagner, T., Leue, C., Pfeilsticker, K., and Platt, U.: Monitoring of the stratospheric chlorine activation by Global Ozone Monitoring Experiment (GOME) OClO measurements in the austral and boreal winters 1995 through 1999, Journal of Geophysical Research: Atmospheres, 106, 4971-4986, https://doi.org/https://doi.org/10.1029/2000JD900458, 2001.

Wagner, T., Wittrock, F., Richter, A., Wenig, M., Burrows, J. P., and Platt, U.: Continuous monitoring of the high and persistent chlorine activation during the Arctic winter 1999/2000 by the GOME instrument on ERS-2, Journal of Geophysical Research: Atmospheres, 107, SOL 3-1-SOL 3-10, https://doi.org/https://doi.org/10.1029/2001JD000466, 2002.

Wahner, A., Tyndall, G. S., and Ravishankara, A. R.: Absorption cross sections for symmetric chlorine dioxide as a function of temperature in the wavelength range 240-480nm, The Journal of Physical Chemistry, 91, 2734-2738, https://doi.org/10.1021/j100295a018, 1987.

Weber, M., Dhomse, S., Wittrock, F., Richter, A., Sinnhuber, B.-M., and Burrows, J. P.: Dynamical control of NH and SH winter/spring total ozone from GOME observations in 1995-2002, Geophysical Research Letters, 30, https://doi.org/https://doi.org/10.1029/2002GL016799, 2003.

Wilmouth, D. M., Hanisco, T. F., Donahue, N. M., and Anderson, J. G.: Fourier Transform Ultraviolet Spectroscopy of the A 2 П3/2 $\longleftarrow$ X 2П3/2 Transition of BrO, The Journal of Physical Chemistry A, 103, 8935-8945, https://doi.org/10.1021/jp991651o, 1999.

Wittrock, F., Richter, A., and Burrows, J. P.: Validation of GOME BrO and OClO observations in the northern hemisphere, Tech. rep., paper presented at European Symposium on Atmospheric Measurements From Space (ESAMS 99), ESA, Noordwijk, Netherlands, 1999.

Wittrock, F., Oetjen, H., Richter, A., Fietkau, S., Medeke, T., Rozanov, A., and Burrows, J. P.: MAX-DOAS measurements of atmospheric trace gases in Ny-Ålesund - Radiative transfer studies and their application, Atmospheric Chemistry and Physics, 4, 955-966, https://doi.org/10.5194/acp-4-955-2004, 2004.

Yela, M., Parrondo, C., Gil, M., Rodríguez, S., Araujo, J., Ochoa, H., Deferrari, G., and Díaz, S.: The September 2002 Antarctic vortex major warming as observed by visible spectroscopy and ozone soundings, International Journal of Remote Sensing, 26, 3361-3376, https://doi.org/10.1080/01431160500076285, 2005.

Yela, M., Gil-Ojeda, M., Navarro-Comas, M., Gonzalez-Bartolomé, D., Puentedura, O., Funke, B., Iglesias, J., Rodríguez, S., García, O., Ochoa, H., and Deferrari, G.: Hemispheric asymmetry in stratospheric $\mathrm{NO}_{2}$ trends, Atmospheric Chemistry and Physics, 17, 13 37313 389, https://doi.org/10.5194/acp-17-13373-2017, 2017. 